\title{
Caracterización mineralógica y petrográfica de las vetas Vizcaya, Octubrina y Gabi del yacimiento aurífero epitermal Zaruma- Portovelo, Ecuador
}

Edgar Berrezueta(1), Berta Ordóñez-Casado(1), Catherine Espinoza-Santos ${ }^{(2)}$, Johnny LoayzaRamírez ${ }^{(2)}$, Paul Carrión-Mero ${ }^{(2)}$, Fernando Morante-Carballo ${ }^{(2,3,4)}$, Wilson Bonilla ${ }^{(2)}$

\author{
(1) Instituto Geológico y Minero de España, CSIC, Oviedo, España \\ e.berrezueta@igme.es, b.ordonez@igme.es \\ (2) Centro de Investigación y Proyectos Aplicados a las Ciencias de laTierra (CIPAT), ESPOL Polytechnic University, \\ Guayaquil 09-01-5863, Ecuador \\ catiespi@espol.edu.ec, jojoloay@espol.edu.ec,pcarrion@espol.edu.ec, fmorante@espol.edu.ec \\ (3) Facultad de Ciencias Naturales y Matemáticas (FCNM), ESPOL Polytechnic University, Guayaquil 09-01-5863, Ecuador \\ (4) Geo-Recursos y Aplicaciones GIGA, ESPOL Polytechnic University, Guayaquil 09-01-5863, Ecuador
}

\begin{abstract}
RESUMEN
La aplicación de las técnicas de microscopía óptica y microsonda electrónica (EMPA) constituye una importante fuente de información en el establecimiento de secuencias evolutivas de fases minerales (paragénesis) y en el apoyo para control y mejora de procesos mineralúrgicos. En este trabajo, se realizó una caracterización mineralógica y petrográfica de tres vetas (Vizcaya, Octubrina y Gabi) pertenecientes al yacimiento epitermal Zaruma-Portovelo (Ecuador). El objetivo principal de este trabajo se centró en la caracterización de las vetas mediante técnicas microscópicas y de microanálisis y, principalmente, en correlacionar la información obtenida con las características geológicas-mineras del yacimiento estudiado. Además, se describió la sistemática desarrollada como un método adecuado para la caracterización y conocimiento básico de áreas mineralizadas.

La caracterización desarrollada mediante microscopía óptica (reflexión y transmisión) y EMPA se complementó mediante microscopía electrónica de barrido, análisis óptico de imágenes y difracción de rayos X. Los resultados obtenidos permitieron: i) la identificación y cuantificación de oro, esfalerita, calcopirita, galena, pirita, hematites, calcosina, covellite y tetraedrita en las probetas pulidas de las vetas estudiadas; ii) la caracterización de las asociaciones minerales presentes en las muestras como complemento a estudios previos de la paragénesis mineral del yacimiento y orientativos en la geometalurgia del yacimiento. La caracterización mineralógica y petrográfica de las menas representa la base del conocimiento para comprender la caracterización del depósito mineral y, complementariamente, mejorar el procesamiento del mineral de interés.
\end{abstract}

Palabras clave: Petrografía de menas, Minerales metálicos, Yacimiento epitermal.

\section{Mineralogical and petrographical characterization of the Vizcaya, Octubrina and Gabi veins from the Zaruma-Portovelo gold epithermal ore deposit (Ecuador)}

\begin{abstract}
Ore petrography through optical microscopy and electron microprobe analysis (EMPA) can be applied to the characterization of ore deposits, allowing accurate and representative information on the evolutionary sequences of mineral phases (paragenesis). In this studywork mineralogical and petrographical characteristics of three veins (Vizcaya, Octubrina and Gabi) of the Zaruma-Portovelo hydrothermal deposit (Ecuador) have been studied. The main objective of this research was to identify and quantify the ore minerals present in the polished section studied by optical microscopy and EPM, and to correlate the data obtained with the previously defined paragenetic evolution. In addition, the systematics we describe is revealed as an appropriate method for the characterization and basic knowledge of the mineralized areas.
\end{abstract}


The mineralogical characterization was completed by scanning electron microscopy, optical image analysis and $X$-ray diffraction. The results have provided us with allowed: i) the identification and quantification of gold, sphalerite, chalcopyrite, galena, pyrite, hematite, chalcocite, covellite and tetrahedrite in the polished sections of the veins studied; ii) the characterization of the mineral associations as a complement to the previous studies of the mineral paragenesis of the deposit and indicative in the geometallurgy of the deposit. The mineralogical and ore petrographical characterization of the ores represent the basis of knowledge to understand the characterization of the mineral deposit and, in addition, improve the processing of the mineral of interest.

Keywords: ore petrography; ore minerals; epithermal.

\section{ABRIDGED ENGLISH VERSION}

\section{Introduction}

The mineralogical and petrographic characterization of the veins we used as a case study was addressed by means of optical microscopy (OpM), optical image analysis (OIA) and scanning electron microscopy (SEM). These techniques have allowed the qualitative analysis of the mineralogy and its correlation with a specific type of mineral deposit. In addition, the petrographic study was complemented with the use of X-ray diffraction (XRD) and electron microprobe (EMPA) analyses. The latter technique showed that precise chemical analysis can be conducted with an accuracy of $1 \%$ and relatively low detection limits providing qualitative and quantitative chemical information of the minerals. The studied samples come from the mineral deposit of Zaruma-Portovelo (Ecuador) (Fig. 1). This deposit consists of a system of veins, the formation of which was a result of hydrothermal processes that gave rise to mineralogical associations of ore and gangue typical of epithermal ore deposits of intermediate sulphidation type. In the deposit, 30 gold veins can be identified with tilts of between 45 and 70 degrees $E$. The main mineralizations are: i) a zone with piritization (without gold), ii) a zone with a predominance of sulphides and the presence of gold (Vizcaya, Octubrina and Gabi veins) (Fig.2) and iii) a zone with a predominance of sulfphosalts and the presence of gold. The main objectives of this study were i) the characterization of the veins through microscopic and microanalytical techniques; ii) the correlation of the obtained information with the geological-mining characteristics of the studied deposit; iii) the description of the process developed as a suitable method for the characterization and basic understanding of the mineralized areas.

\section{Methodology}

The procedure of petrographic and geochemical characterization of metal ores included four main stages (Fig. 3): the first stage addressed the selection of representative samples and the visual characterization of the ore. The second stage consisted of qualitative and quantitative characterization of polished specimens and thin sections using OpM, OIA, SEM and was complemented with XRD. In the third stage, geochemical characterization of the mineral phases was carried out through the use of EMPA. The final stage focused on the correlation of the information obtained with the different techniques with previous studies.

\section{Mineralogical characterization and microanalysis by electron microprobe}

The study of all the hand samples and polished specimens prepared for this study (Table 1) have allowed the identification of 8 main opaque minerals (Figs 4 and 5): sphalerite, chalcopyrite, pyrite, galena, tetrahedrite, chalcocite, covellite and hematite. The study by SEM (Fig. 6) and DRX (Table 2) have allowed us to determine the presence of $\mathrm{Au}$ and $\mathrm{Ag}$ in the metallic minerals. Optical image analysis made the automated identification and quantification of the mineral (opaque) phases possible in 6 specimens (M1_A_Es, M2_A_Es, M2_B_Es, M3_A_Es, M4_B_Es and M4 $\left.B b_{-} E s\right)$ (Fig. 7). In addition, general criteria for the application of this technique were defined. SpecificaIly, we defined segmentation values of the identified minerals, for the $R, G$ and $B$ bands in the grey level values (Fig. 7). For the quantification of abundance (area) of the minerals, 200 images (10X) were used for each polished specimen. The chemical composition of the different zones of selected mineral phases $(132$ analyzes) was studied by EMPA and expressed as weight percentage of the chemical elements. The mineral identification was carried out by means of converting these percentages into chemical formulas. All the acquired data is presented in Annex 1 and, in detail, in Table 3 for the minerals present in each vein.

\section{Interpretation and discussion of results}

The defined mineralizations and their paragenetic interpretation for the three veins are shown in Figure 8. This interpretation was based on correlating the mineralizations and their (petrographic and geochemical) peculiarities considering previous studies. The estimation of the abundance of the main mineral phases (Ccp, Py and Gn) with Au content, through OIA and using EMPA data (Annex 1), is presented in Figure 9. Using the quantification process proposed, more specific and automated details could be obtained in the geometallurgical optimization such as the degree of mineral release, size and distribution of the mineral 
grains and textural data.

\section{Conclusions}

From the methodological point of view, the techniques (OpM, OIA, SEM, XRD and EMPA) used in the characterization of the samples from three veins permitted the efficient identification and quantification of the main mineral phases. In terms of the obtained results, it was possible to establish that, according to the mineralizations and mineral associations found, these correspond to an epithermal intermediate sulphidation deposit, as described in the scientific literature. Furthermore, the studied samples (mining work fronts in the Vizcaya, Octubrina and Gabi veins) correspond to mineralization stages with an economic value. That is, they belong to the stadiums (2-3-4) where the deposit of polymetallic sulphides with gold and silver-gold contents occurred.

\section{Introducción y Objetivos}

Los depósitos hidrotermales volcánicos-subvolcánicos representan una importante fuente de minerales como plata, cobre, zinc y oro (Einaudi et al. 2005; Fontaine et al. 2009; Reeves et al. 2011). Dado que la mineralización en este tipo de yacimientos se presenta principalmente como venas, su estudio y caracterización es clave en la comprensión del depósito (Fournier, 1999; Rusk et al. 2008; Von Damm, 2004). Los yacimientos epitermales son acumulaciones de metales base y metales preciosos procedente de fluido hidrotermal ascendente a profundidades relativamente poco profundas $( \pm 1.5 \mathrm{~km})$ y a temperaturas relativamente bajas ( 150 y $300^{\circ} \mathrm{C}$ ) (Hedenquist et al. 2000; Simmons et al. 2005). Estos yacimientos están ligados a procesos volcánicos en zonas de subducción (márgenes activos) y, teóricamente, la mineralización ocurre a escasa profundidad en la corteza. En general, son atractivos para el aprovechamiento de oro $(\mathrm{Au})$ y plata $(\mathrm{Ag})$. Los depósitos se clasifican en yacimientos epitermales de baja sulfuración, intermedia sulfuración y alta sulfuración, según el pH / Eh de los fluidos mineralizantes y de la asociación de minerales presente (John et al. 1999; Hedenquist et al. 2000). Los depósitos epitermales de sulfuración intermedia están representados habitualmente por asociaciones de pirita + esfalerita (pobre en Fe) + galena + calcopirita + tetraedrita (Einaudi et al. 2005, Wang et al. 2019). Entre los metales preciosos se presentan electrum, oro nativo, argentita, sulfosales (con Ag) y, en menor ocurrencia, arsenopirita (Gemmell et al. 1988) y pirrotita (Pearson et al. 1988). La relación de Ag:Au para estos depósitos por lo general son de 10:1 y el contenido de sulfuro es variable de $1 \mathrm{a}>10 \%$ (Albinson et al. 2001). Unos ejemplos de estos depósitos son: Yacimiento Guanajuato (México), Creede (Estados Unidos), Pallancata (Perú) y San Cristóbal (Bolivia) (Wang et al. 2019).
La mineralogía y la petrografía detallada de los minerales y rocas que componen un yacimiento constituyen no sólo una información fundamental para su caracterización. Esta información resulta también básica en el diseño y modelado de operaciones de procesamiento de minerales (geometalurgia). De acuerdo con Craig and Vaughan (1994), tanto la caracterización de yacimientos minerales como el desarrollo de modelos geometalúrgicos requieren herramientas efectivas y complementarias que permitan la identificación y cuantificación mineralógica. El microscopio óptico (MOp) de reflexión es el instrumento básico e indispensable en el estudio petrográfico de menas para la identificación de los minerales opacos y su relación (Randohr, 1969; Criddle, 1990). El reconocimiento automatizado de menas metálicas mediante análisis óptico de imágenes (AOI) representa un complemento de estudios de microscopía de menas, proporcionando un eficaz soporte numérico para la cuantificación de parámetros geométricos y densitométricos de los minerales (Köse et al. 2012; Leroy and Pirard, 2019; Chopped et al. 2019). En los últimos años, los sistemas de caracterización mineralógica basados en microscopía electrónica han permitido mejoras importantes en la caracterización de minerales opacos respecto al MOp en casos de caracterización de yacimientos minerales (Echavarría et al. 2005; Song et al. 2019) y geometalurgia (Hrstka et al. 2018; Honeyands et al. 2019).

En el presente caso de estudio, la identificación y cuantificación de fases minerales se abordó mediante microscopio óptico (MOp), análisis óptico de imágenes (AOI) y microscopio electrónico de barrido (MEB). Estas técnicas, de acuerdo con Castroviejo and Berrezueta (2009), Gao et al. (2014), Surour et al. (2014) permiten la identificación de las mineralogías en las muestras evaluadas $y$, principalmente, correlacionar éstas con una tipología específica de yacimiento mineral. Además, el estudio petrográfico fue complementado con la utilización de difracción de rayos $X$ (DRX) y de microsonda electrónica (EMPA). Esta última técnica permite un análisis puntual con una precisión del $1 \%$ y unos límites de detección relativamente bajos proporcionando una información química cualitativa y cuantitativa de minerales.

El depósito mineral Zaruma-Portovelo, localizado al SO del Ecuador, está relacionado a un arco continental de lava andesítica con vetas de cuarzo-sulfuros (Vikentyev et al. 2005). Las vetas del depósito son discontinuas y con orientación predominante N-S y con buzamientos preferenciales hacia el Este (BoniIla, 2010). Cabe indicar que el estudio se realizó en el sistema Vizcaya-Nicole descrito por Bonilla (2010), el cual incluye de Oeste a Este las vetas: Vizcaya, Octubrina, Gabi, Elizabeth y Nicole.

El objetivo de este estudio está enfocado a la caracterización mineralógica de los minerales metálicos de las vetas Vizcaya, Octubrina y Gabi, perteneciente al sistema Vizcaya-Nicole, mediante técnicas como MOp, AOI, MEB, DRX y EMPA, con el fin de i) estable- 
cer la mineralización presente y correlacionar ésta con la paragénesis del yacimiento establecida en trabajos previos (Bonilla, 2010; Vikentyev et al. 2005; Berrezueta et al. 2006) y ii) aportar información orientativa en geometalurgia. Además, se pretende describir la sistemática desarrollada como método adecuado en la caracterización de áreas mineras, concretamente, en el conocimiento y comprensión de la evolución mineralógica del yacimiento y en actividades relacionadas a la recuperación mineral (procesos mineralúrgicos). Es importante entender que las medidas y análisis realizados sobre las muestras (de mano, probetas pulidas y secciones delgadas) son representativas a su respectiva escala. A escala de las vetas y de todo el depósito, los resultados deben considerarse como orientativos.

\section{Marco geológico y mineralización}

El yacimiento mineral de Zaruma-Portovelo (Ecuador) se localiza en la zona Sur de la Cordillera Occidental de los Andes Ecuatorianos (Figura 1a), donde predominan rocas de la corteza oceánica y de arco isla (Litherland and Aspden, 1992). Las mineralizaciones en este sector de la Cordillera se encuentran asociadas generalmente a un magmatismo calcoalcalino de composición química desde bajo a alto contenido en potasio (Kay et al. 1999). Este magmatismo es el responsable de la formación de las rocas ígneas presentes en la zona de estudio, mediante procesos de asimilación y cristalización fraccionada en profundidades inferiores a 20 kilómetros desde la superficie. Según Chiaradia et al. (2004), los depósitos minerales de tipo epitermal en Ecuador, en el que el depósito de Zaruma-Portovelo puede incluirse (Paladines and Rosero, 1996), están asociados genéticamente con la actividad ígnea desarrollada desde el Eoceno al Mioceno tardío (50-9 Ma).

Las litologías predominantes, en las que encajan las mineralizaciones, son lavas andesíticas, basaltos, lavas volcánicas félsicas, piroclastos, flujos riolíticos y plutones de composición diorítica a granodiorítica (Van Thournout et al. 1996).

El yacimiento de Zaruma-Portovelo consiste en un sistema de vetas cuya formación responde a procesos hidrotermales (Spencer et al. 2002; Banda et al. 2005) que han dado lugar a asociaciones mineralógicas de mena y ganga típicas de un yacimiento epitermal de sulfuración intermedia (Paladines and Rosero, 1996), acorde con las características definidas por Hedenquist et al. (2000), Hedenquist (2001). Según Vikentyev et al. (2005) en este depósito se pueden identificar 30 vetas auríferas con buzamientos entre 45 y 70 grados $\mathrm{E}$. Tres tipos de mineralizaciones principales fueron definidas por Banda et al. (2005) y Vikentyev et al. (2005): i) zona con piritización (sin oro), ii) zona con predominio de sulfuros y presencia de oro (vetas Vizcaya, Octubrina y Gabi) y iii) zona de predominio de sulfosales con presencia de oro.
Según Van Thournout et al. (1996), las alteraciones hidrotermales que pueden observarse en el depósito de Zaruma-Portovelo son del tipo: propilítica, argílica, sílica y sericítica, definidas en base a los estudios de Meyer and Hemley (1967) y Heald et al. (1987). De acuerdo con Billingsley (1926) y Vikentyev et al. (2005), la disposición de las vetas en el distrito minero presenta una orientación preferente NS, que está asociada a un trend de fracturación regional de orientación NO-SE, representado fundamentalmente por las fallas Palestina al Norte y Piñas al Sur. (Figura 1b). El bloque está compuesto mayoritariamente por lavas andesíticas y diques y stocks riolíticos subvolcánicos. Este bloque está dividido en tres series de acuerdo a la composición química de las rocas encajantes, siguiendo la secuencia de Oeste a Este, con las series Faique, Portovelo y Muluncay (Figura 1c).

De acuerdo con Paladines and Rosero (1996), las principales asociaciones minerales en la zona estudiada y en particular en el filón Vizcaya corresponden a: cuarzo + feldespatos + esfalerita y clorita + pirita. En estudios posteriores, Bonilla (2002) añadió hematites a la asociación antes definida. A principios del siglo XXI, Vikentyev et al. (2005) y Banda et al. (2005) definieron nuevas asociaciones mineralógicas para el filón Vizcaya: cuarzo + pirita + calcopirita, cuarzo + galena + esfalerita + tetraedrita + tenantita + oro + cuarzo + carbonatos, corroborando en su mayor parte lo estudiado por Bonilla (1996). Posteriormente, Bonilla (2010) propuso una evolución paragenética para el filón Vizcaya en 5 estadios de mineralización (Figura 2). En detalle, propone en su modelo: un primer estadio (e1) en el que se presenta un predominio de alteración propilítica; un segundo estadio (e2) que presenta unas alteraciones propilíticas, sílicas y fílicas; un tercer estadio (e3), catalogado como el de interés económico, que presenta alteraciones propilíticas, argílicas, silícas y fílicas; un cuarto estadio (e4) que presenta argilización y silicificación; y un quinto estadio (e5) que presenta una silicificación intensa.

En los últimos años, Berrezueta et al. (2016), abordaron la identificación y estimación cuantitativa de las principales fases minerales presentes en las vetas Vizcaya, Sanzón, Azul, LaY y Guabo Verde, encontrando oro, esfalerita, galena, pirita, pirrotina, bornita, hematites, calcosina, pentlandita, covelina, tetraedrita y bismuto nativo, en concordancia con los estudios previos de Paladines and Rosero (1996), Vikentyev et al. (2005) y Banda et al. (2005).

\section{Materiales y Métodos}

El procedimiento para la caracterización petrográfica y geoquímica de las menas metálicas incluyó cuatro principales etapas (Figura 3): la primera etapa abordó la selección de muestras representativas y la caracterización visual de la mineralización. La segunda etapa consistió en la caracterización cualitativa y cuantitativa de probetas pulidas y láminas delgadas mediante 
(a)

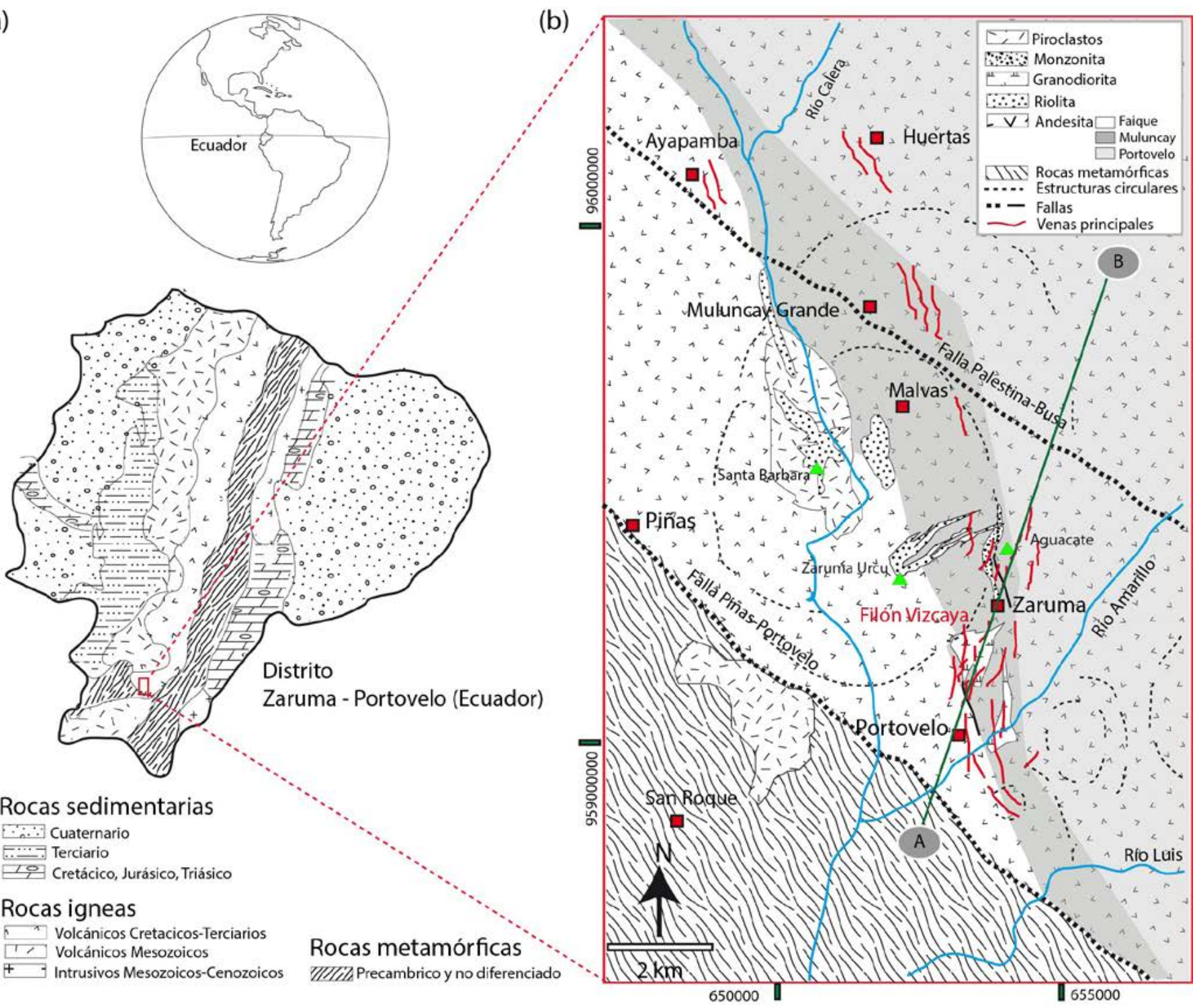

(c)

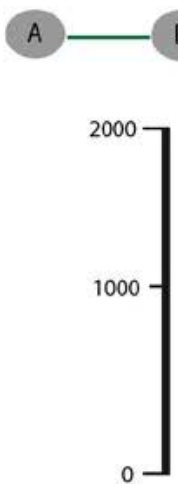



Figura 1. (a) Mapa geológico simplificado de Ecuador y localización del área de estudio; b) mapa del distrito Zaruma-Portovelo, contiene las principales formaciones geológicas, estructuras y venas mineralizadas; y (c) corte geológico SW-NE (A-B). Modificado de VanThournout et al. (1996), Bonilla (2010) y Berrezueta et al. (2016).

Figure 1. (a) Simplified geological map of Ecuador and the location of the selected area; (b) geological maps of the Zaruma-Portovelo gold field with basic geology (volcanic and intrusive rocks), principal structures and relevant veins; and (c) geologic sketch SW-NE (A-B). Modified from Van Thournout et al. (1996), Bonilla (2010) and Berrezueta et al. (2016). 
MOp, AOI, MEB y complementada con XRD. En la tercera etapa se llevó a cabo la caracterización geoquímica de las fases minerales mediante la utilización de EMPA. La etapa final se enfocó en la realización de la correlación de la información obtenida con las diferentes técnicas aplicadas y respecto a la procedente de estudios previos.

Las zonas seleccionadas para la toma de muestras de las mineralizaciones del depósito estudiado correspondieron a frentes de explotación de la Mina de la Empresa Bira S.A., con mineralización significativa de oro, plata y cobre. Para cada una de las vetas de interés se tomaron muestras de mena en frentes de explotación (Figura 3a) de un peso aproximado de $3 \mathrm{Kg} \mathrm{c/u}$. Se recolectaron en total muestras de 4 estaciones (Tabla 1): una muestra para la veta Vizcaya dos muestras para la veta Octubrina y otra muestra para la veta Gabi.

Las muestras seleccionadas para la caracterización petrográfica y geoquímica se prepararon como pro- betas pulidas y láminas delgadas (Tabla 1) utilizando los equipos GEOFORM (cortadora de muestras) y FORCIMAT (pulido de muestras) disponibles en el Laboratorio de Petrografía de la Escuela Superior Politécnica del Litoral (Ecuador). La elaboración de las secciones se basó en el procedimiento descrito por Kehl (1954). Con el fin de garantizar la homogeneidad de la superficie de las probetas pulidas se aplicaron los procedimientos de corrección de pulido descritos por Castroviejo et al. (1999).

El estudio petrográfico de las probetas pulidas y láminas delgadas se realizó mediante un microscopio óptico de reflexión/transmisión (Leica DM 6000) (Figura 3b). La cuantificación de fases minerales (opacos) mediante procesamiento de imágenes se realizó mediante la utilización de i) una cámara digital Prog Res-5 (5.0 Megapixeles, Color, 2/3 pulgadas, interfase IEEE-1394) acoplada a un microscopio (Leica DM $6000)$, ii) un programa de tratamiento de imágenes
Tipo de Mineralización

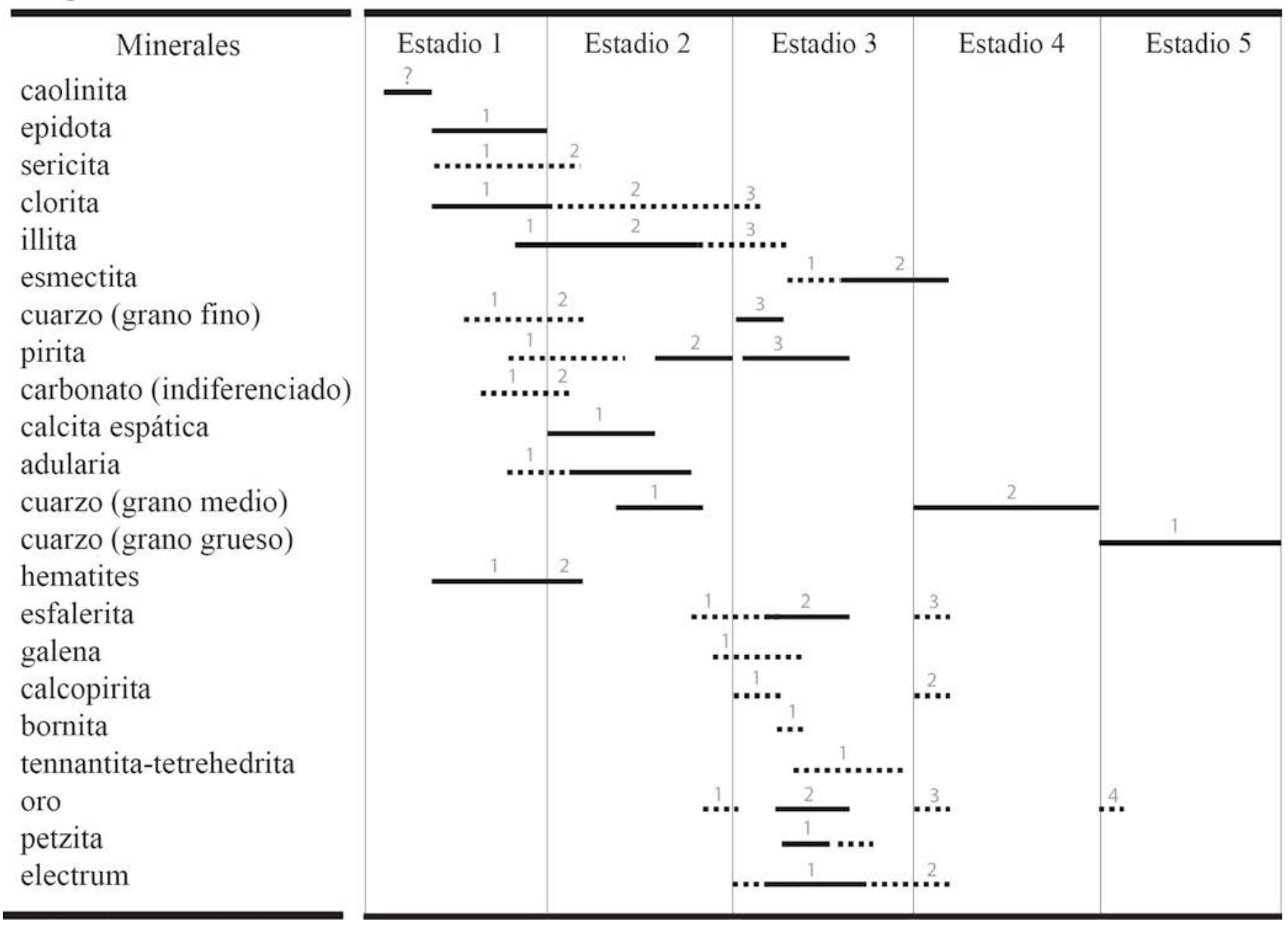

Figura 2. Paragénesis de la Veta Vizcaya con la evolución de minerales depositados en cada estadio (5) durante el evento hidrotermal de mineralización (Bonilla, 2010).

Figure 2. Paragenesis of the Vizcaya Vein with the evolution of the minerals deposited in each stage (5) during the mineralization hydrothermal event (Bonilla, 2010).

Hidrotermal 

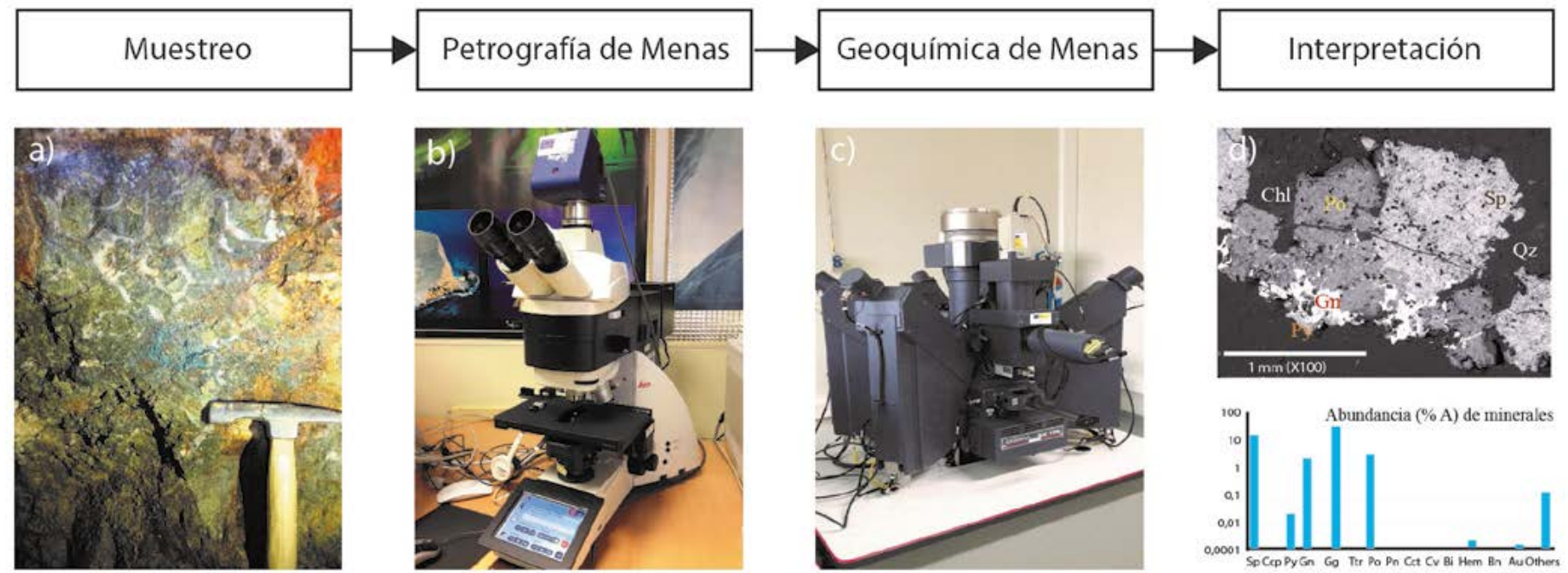

Figura 3. Secuencia esquemática de las etapas de trabajo abordadas: (a) muestreo de materiales en minas Bira (Ecuador); (b) MOp para estudio de probetas pulidas (IGME, Oviedo); (c) EMPA para análisis químicos (UNIOVI, Oviedo); (d) ejemplo de interpretación de imágenes minerales adquiridas con MEB y de cuantificación de fases minerales mediante AOI.

Figure 3. Schematic representation of the sequence followed in this study: (a) sampling of ore samples from the Bira Mine (Ecuador); (b) OpM for the study of polished specimens (IGME, Oviedo); (c) EMPA for chemical analysis (UNIOVI, Oviedo); (d) example of interpretation of the mineral images acquired with MEB and of quantification of mineral phases by means of OIA.

(ImageJ 1.50i) instalado en un I-Mac 5 (Montain MacOs $\mathrm{x}$ 10.8) y iii) una macro específica (Berrezueta et al. 2016) para la clasificación y cuantificación de las fases minerales estudiadas. El análisis se llevó a cabo sobre imágenes en color basadas en el modelo Rojo $(R)$, Verde (V), Azul (A) de 24 bits (cada banda -8 bitsestá representada por valores entre 0 a 255 niveles de gris) y con un tamaño de imagen de 1294 x 974 píxels. Con la utilización de unos aumentos de 10x, cada píxel equivalió a 0.624 micras, aunque se consideró como fase mineral aquella con representación superior a 4 píxeles. Los estudios cualitativos y cuan- titativos se desarrollaron en la Unidad de Oviedo de Instituto Geológico y Minero de España.

El difractómetro utilizado para la identificación y cuantificación de minerales ha sido un PANalytical XPert Pro ( $35 \mathrm{kV}, 40 \mathrm{~mA}$ ) ubicado en el Laboratorio LEMAT de la Escuela Superior Politécnica del Litoral (Ecuador). Para la cuantificación de las fases minerales se utilizó un $10 \%$ de $\mathrm{ZnO}$ como patrón. Los estudios mediante microscopio electrónico se realizaron mediante un equipo JEOL $6100 \mathrm{MEB}$, con filamento de W, usando un voltaje de aceleración de $20 \mathrm{kV}$, y se procesaron mediante el software Inca Energy-200.

\begin{tabular}{|c|c|c|c|c|c|c|c|}
\hline \multirow{2}{*}{ Mina } & \multicolumn{2}{|c|}{ Localización (UTM) } & \multirow{2}{*}{ Veta } & \multirow{2}{*}{$\begin{array}{c}\text { Muestras de } \\
\text { mano }\end{array}$} & \multirow{2}{*}{$\begin{array}{l}\text { Láminas } \\
\text { delgadas }\end{array}$} & \multicolumn{2}{|c|}{ Probetas pulidas } \\
\hline & $\mathbf{x}$ & $\mathbf{y}$ & & & & Ecuador & España \\
\hline \multirow{4}{*}{ Q $1 / 2$} & 653852 & 9593224 & Vizcaya & MV-1 & M_ $3 \mathrm{~A}$ & M_3A_Ec & M_3A_Es \\
\hline & 653826 & 9592939 & Octubrina & MO-1 & M_1A & $\begin{array}{l}\text { M_1A_Ec, } \\
\text { M_2A_Ec }\end{array}$ & M_1A_Es \\
\hline & 653792 & 9592950 & Octubrina & MO-2 & & & $\begin{array}{l}\text { M_2A_Es, } \\
\text { M_2B_Es }\end{array}$ \\
\hline & 653915 & 9593059 & Gabi & MG-1 & M_4B & M_4B_Ec & $\begin{array}{l}\text { M_4B_Es, } \\
\text { M_4Bb_Es }\end{array}$ \\
\hline
\end{tabular}

Tabla 1. Información general de las muestras recolectadas y seleccionadas.

Table 1. General information about the collected and selected ore samples. 
Los estudios mediante microsonda electrónica se llevaron a cabo en los Laboratorios de los servicios científico-técnicos de la Universidad de Oviedo (España) usando un equipo (CAMEBAX SX-100) (Figura 3c). La microsonda utilizada está dotada con cinco espectrómetros de dispersión por longitud de onda (WDS) y con detectores de electrones secundarios, electrones retrodispersados y de catodoluminiscencia. Los elementos mayores y trazas fueron determinados a unas condiciones de operación de: $20 \mathrm{kV}$ (voltaje de aceleración), $20 \mathrm{nA}$ (corriente del haz), $2 \mu \mathrm{m}$ (tamaño de la sonda), 10-180 s (tiempo de contaje de rayos $\mathrm{X}$ ) y 5-90 s (tiempo de contaje del fondo). Las señales analizadas fueron: $\mathrm{Cu} \mathrm{Ka}$, As La, Fe Ka, Co Ka, Ni Ka, S Ka, Ag La, Sb La, Te La, Au La, Bi La, Zn Ka, Se La, Sn La, $\mathrm{Hg} \mathrm{La}, \mathrm{Pb} \mathrm{Ma}, \mathrm{Mn} \mathrm{Ka}, \mathrm{Cd} \mathrm{La}$. Los límites de detección se presentan en el Anexo 1. Los límites de detección de los elementos evaluados en detalle en este trabajo fueron para el Au de $289 \mathrm{ppm}$, para la $\mathrm{Ag}$ de $180 \mathrm{ppm}$, para el Cu de 106 ppm, para el Fe de 204 ppm y para el As de 120 ppm. Los patrones utilizados fueron: Ag, $\mathrm{Au}, \mathrm{Bi}, \mathrm{Co}, \mathrm{Mn}, \mathrm{Ni}, \mathrm{Se}, \mathrm{PbS}, \mathrm{FeS}_{2}, \mathrm{PdTe}_{2}, \mathrm{Sb}_{2} \mathrm{~S}_{3^{\prime}}, \mathrm{CuFeS}_{2}$ $\mathrm{ZnS}, \mathrm{HgS}, \mathrm{SNO}_{2}$, FeAsS.

La correlación entre los datos de campo, la caracterización mineralógica y la caracterización geoquímica de la mineralización de las menas estudiadas (Figura 3d) permitió mejorar la información mineralógica-geoquímica obtenida de estudios previos y, complementariamente, realizar una valoración crítica del procedimiento desarrollado en la caracterización de estos depósitos minerales.

\section{Resultados: Caracterización de la mineralógica}

\section{Inspección visual}

La identificación de los minerales opacos presentes en las muestras de mano (MV-1, MO-1 y MG-1) toma-
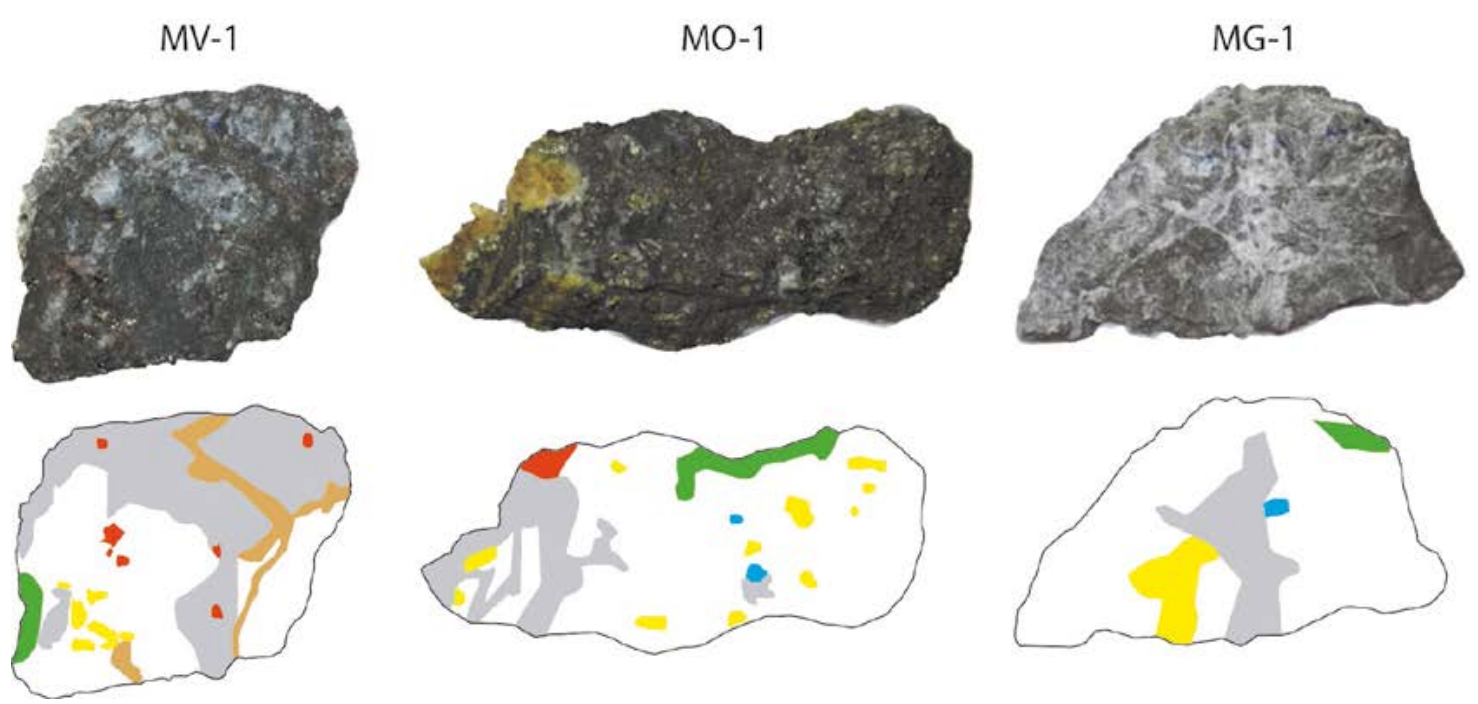

das se detallan en la Figura 4. Los minerales descritos corresponden a las especies minerales distinguibles mediante inspección visual. La mineralización identificada en las muestras de mano (pirita, calcopirita, galena, esfalerita, hematites, covellina y cuarzo) y sus asociaciones preferentes (calcopirita-pirita-esfalerita) permitieron corroborar que las muestras poseen una mineralización similar a la establecida para el depósito. La identificación y localización de la mineralización en las muestras permitió orientar la tarea de selección de las muestras para la elaboración de probetas pulidas.

\section{Microscopía óptica}

El estudio de la totalidad de probetas pulidas elaboradas para este trabajo (Tabla 1) permitió la identificación de 8 minerales opacos principales: esfalerita, calcopirita, pirita, galena, tetraedrita, calcosina, covellina y hematites. En el caso de la muestra de la veta Vizcaya, se observó la presencia de tres fases de cuarzo diferenciables por su textura y composición: a) cuarzo masivo con diseminados de sulfuros; b) cuarzo rellenando fisuras con presencia de pirita, calcopirita y hematites; c) cuarzo granular con intercrecimientos de calcopirita. Además, fue posible identificar tres fases de pirita: la pirita 1 presente como pequeños cristales subhedrales diseminados en cuarzo, la pirita 2 presente de forma masiva con una marcada fracturación y un evidente proceso de reemplazamiento pseudomorfo a esfalerita y, finalmente, a partir de los datos químicos, la pirita 3 también de tipo masivo presentando contenidos de oro y plata. En el caso de la esfalerita, se observa que un tipo de esfalerita (esfalerita 1) aparece remplazada por pirita y con forma anhedral mientras que, una esfalerita posterior (esfalerita 2), presenta abundantes exsoluciones de calcopirita.

En las muestras de la veta Octubrina, las fases minerales predominantes son cuarzo con calcopirita y

Figura 4. Fotografía de muestras de mano e identificación de la mineralización principal.

Figure 4. Photographs of hand specimens and sketches with the principal identified ore minerals. 


M_3A_Es
(Vizcaya)

M_1A_Es
(Octubrina)

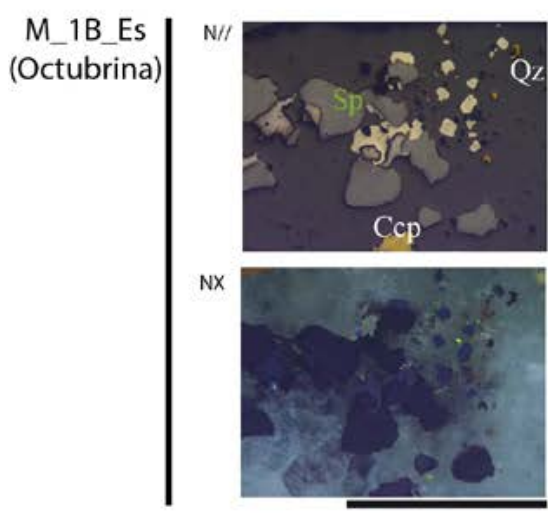

$$
\underset{(\text { Gabi) }}{\text { M_4B_Es }}
$$
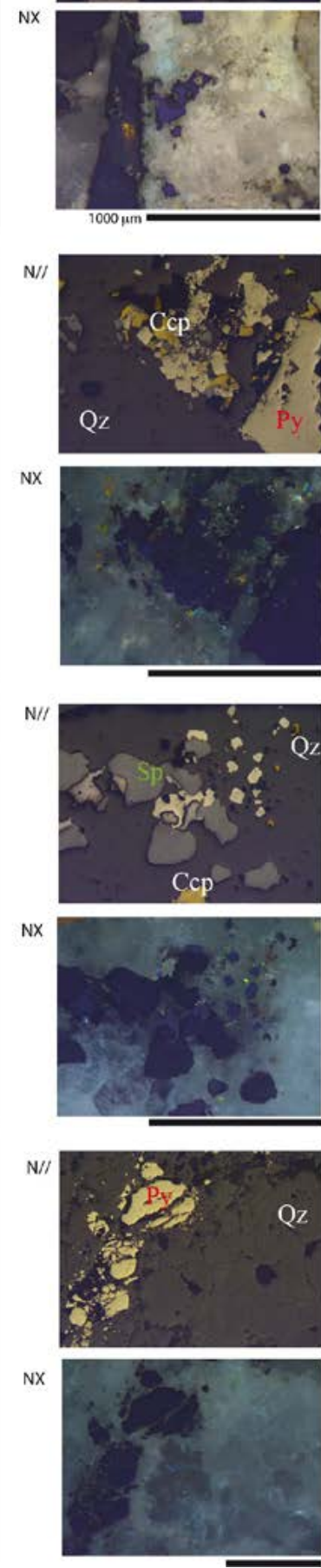

NX
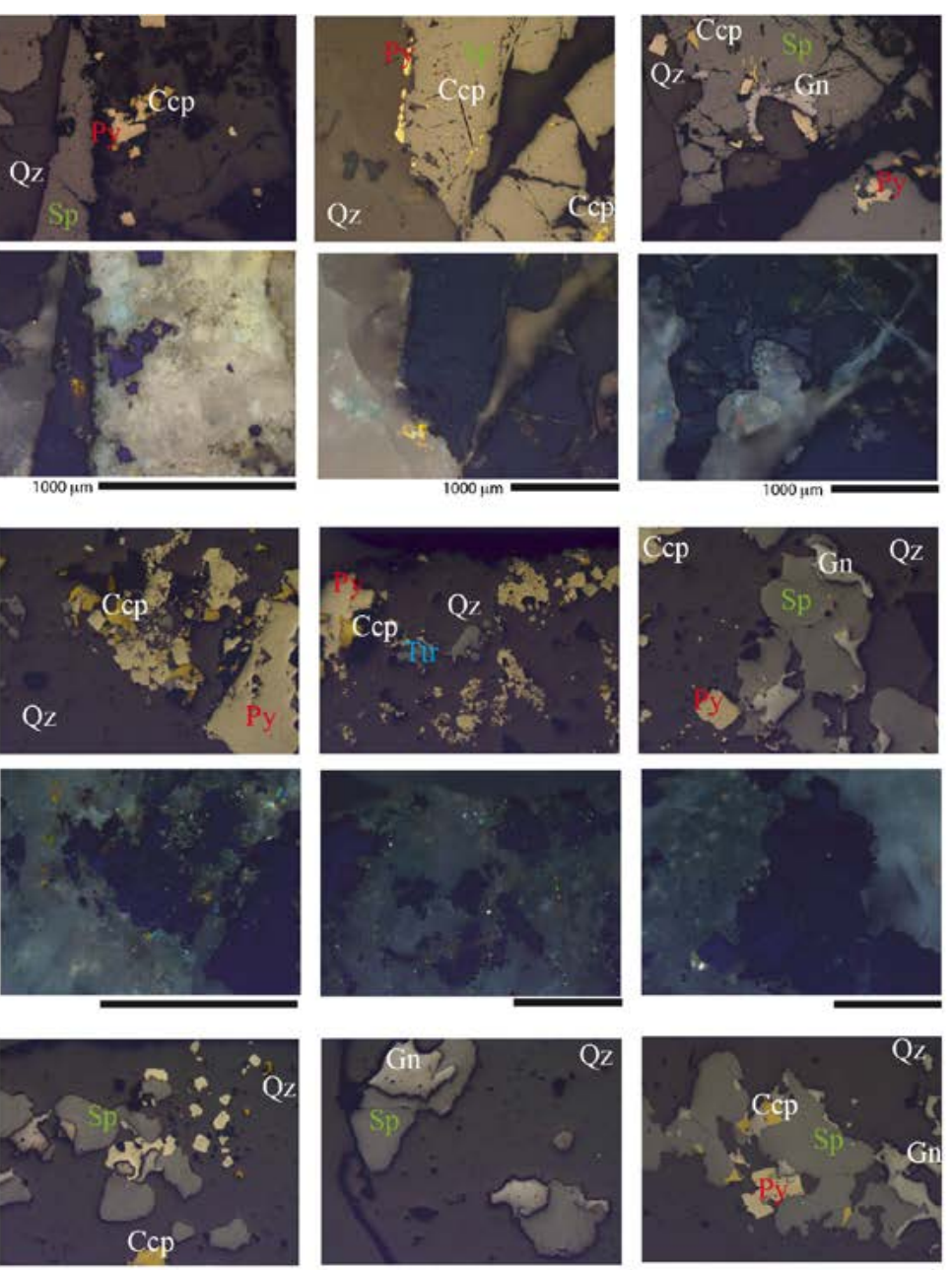

Componentes mayores ( $>5 \%$ por volumen) Componentes menores ( $<5 \%$ por volumen) Py, Ccp, Gn escasos ( $<1 \%$ por volumen): Cct, Hem

Textura: Diseminada
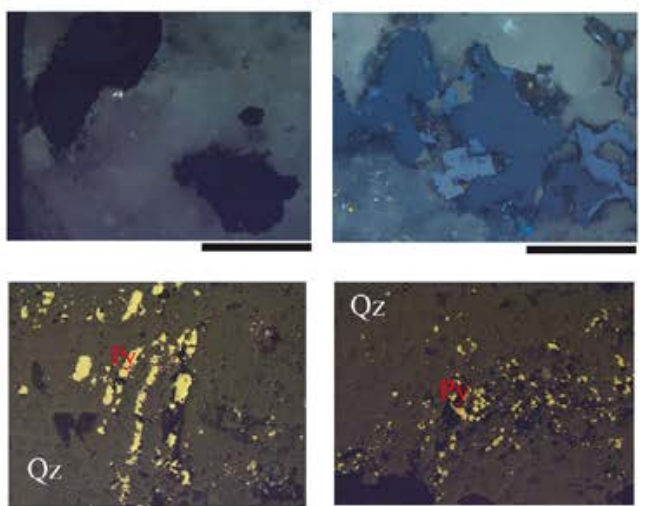

Componentes mayores ( $>5 \%$ por volumen):

$\mathrm{Qz}, \mathrm{Py}$

Componentes menores ( $<5 \%$ por volumen) escasos ( $<1 \%$ por volumen) Gn, Hem

Textura: Diseminada
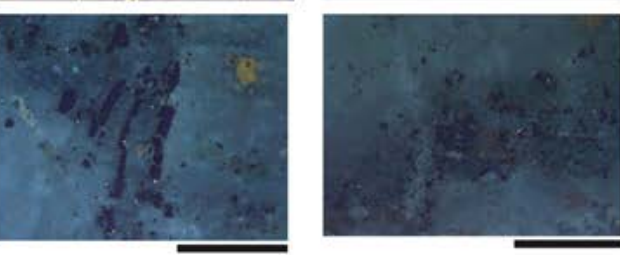

Figura 5. Mineralización de probetas pulidas visible con luz reflejada y descripción resumida. Esfalerita (Sp), calcopirita (Ccp), pirita (Py), galena $(\mathrm{Gn})$, ganga $(\mathrm{Gg})$, tetrahedrita $(\mathrm{Ttr})$, calcosina $(\mathrm{Cct})$, covellina $(\mathrm{Cv})$, hematites (Hem), oro (Au), otros (sin identificar). Abreviaturas de minerales según Whitney and Evans (2010).

Figure 5. Reflected light photomicrographs and summary of the ore description of four polished sections. Sphalerite (Sp), chalcopyrite (Ccp), pyrite (Py), galena (Gn), gangue (Gg), tetrahedrite (Ttr), chalcocite (Cct), covellite (Cv), hematite (Hem), gold (Au), Others (unidentified). Mineral abbreviations after Whitney and Evans (2010). 
calcopirita con inclusiones de pirita, presentando alteraciones de tipo halo a covellina. Además, se encuentran cristales subhedrales de galena aislados. Aparecen también cristales grandes de pirita fracturados $y$ rellenando esas fracturas hay calcopirita, esfalerita, tetraedrita y arcillas. El cuarzo en las muestras de Octubrina presentan las mismas características que las observadas en la veta Vizcaya.

Las muestras de la veta Gabi presentan tres fases de cuarzo: a) una fase de cuarzo microgranular y masivo con pirita subhedral brechificada; b) una fase de cuarzo con pocos sulfuros que intruye al cuarzo de primera fase; c) un evento con cuarzo granular con inclusiones de pirita subhedral.

En cuanto a la textura general de la mineralización para todas las muestras estudiadas, está definida como un relleno hidrotermal caracterizado por texturas de relleno de fisuras y con texturas de reemplazamiento locales. Los resultados del estudio microscópico de algunas probetas pulidas (M_3A_Es, M_1A_Es, M_1B_Es, M_2A_Es, M_4B_Es y M_4Bb_Es) se presentan en la Figura 5 , donde mediante imágenes representativas, se describen las principales minera-

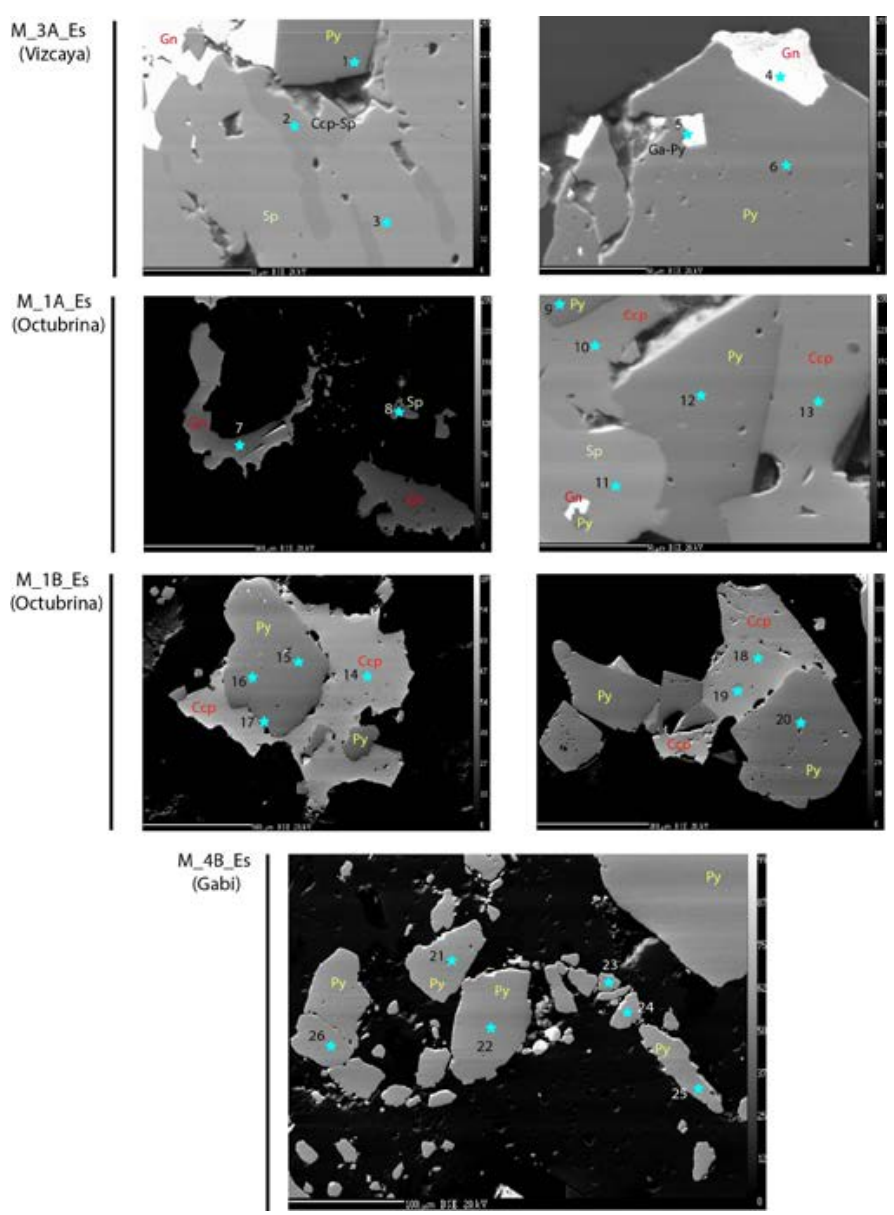

Figura 6. Mineralización de cuatro probetas pulidas mediante MEBEMPA.

Figure 6. SEM photomicrographs and summary ore description of four polished sections. lizaciones y texturas a escala de probeta pulida. En un contexto más general, los filones presentan unas texturas de relleno con mineralizaciones bandeadas, coloformes, oquerosas y también, en algunos casos, diseminadas. En la roca encajante, la mineralización no es predominante y tiene un carácter diseminado resultado de un remplazamiento poco frecuente.

La caracterización de la ganga del depósito se llevó a cabo mediante el estudio de tres muestras (M_1A, M_3A, M_4B) mediante microscopía óptica de transmisión. Ésta permitió la identificación de tres minerales principales: cuarzo, feldespato y clorita.

\section{Microscopía electrónica y DRX}

Como complemento a los estudios con MOp se estudiaron cuatro muestras (M_3A_Es, M_1A_Es, M_1B Es y M_4B_Es) mediante MEB-EMPA con el fin de determinar la presencia de $\mathrm{Au}$ y $\mathrm{Ag}$ en los minerales metálicos previamente definidos. Los resultados obtenidos (Figura 6) en cuanto a la mineralogía, textura y asociaciones minerales concuerdan con los establecidos en los trabajos previos realizados (Vikentyev et al. 2005 y Banda et al. 2005) y, concretamente, en la presencia de $\mathrm{Au}$ y $\mathrm{Ag}$ no visibles en sulfuros.

El análisis mediante DRX permitió la identificación cualitativa mediante patrones de difracción y la cuantificación de las fases minerales presentes en tres muestras de las vetas estudiadas (M_3A_Ec, M_1A Ec, M_4B_Ec). Los resultados de la identificación y cuantificación se presentan en la Tabla 2. En ella se puede observar una variación en el porcentaje de la

\begin{tabular}{|c|c|c|c|}
\hline Minerales & $\begin{array}{c}\text { M_3A_Ec } \\
\text { Veta Vizcaya } \\
\%\end{array}$ & $\begin{array}{c}\text { M_1A_Ec } \\
\text { Veta Octubrina } \\
\%\end{array}$ & $\begin{array}{c}\text { M_4B_Ec } \\
\text { Veta Gabi } \\
\%\end{array}$ \\
\hline Cuarzo & 54.30 & 48.70 & 46.30 \\
\hline Calcopirita & 1.40 & 8.00 & - \\
\hline $\begin{array}{c}\text { Filosilicato } \\
\text { (Clurita) }\end{array}$ & 1.70 & 5.80 & 2.60 \\
\hline Pirita & 6.80 & 9.30 & 2.30 \\
\hline Esfalerita & 0.20 & 0.60 & - \\
\hline Feldespato & - & -. & 21.30 \\
\hline Biotita & - & - & 3.40 \\
\hline Amorfo & 25.50 & 17.50 & 14.00 \\
\hline
\end{tabular}

Tabla 2. Identificación y cuantificación de minerales mediante DRX. Table 2. Identification and quantification of the minerals by XRD. 
ganga (cuarzo) y en los sulfuros como pirita, calcopirita y una menor variación de la esfalerita.

\section{Análisis Óptico de Imágenes}

El análisis óptico de imágenes permitió la identificación y cuantificación de manera automatizada de las fases minerales (opacos) presentes en 6 probetas (M1_A_Es, M2_A_Es, M2_B_Es, M3_A_Es, M4_B_Es Y M4_Bb_Es). La identificación de los minerales se logró al establecer los rangos de segmentación de éstos especificados en la Figura 7a. Los valores de segmentación para las bandas $\mathrm{R}, \mathrm{V}$ y $\mathrm{A}$ fueron definidos específicamente para los minerales identificados en las probetas pulidas mediante unas ventanas de muestreo de $10 * 10$ pixeles, en valores de nivel de gris. En la cuantificación de abundancia (área) de los minerales se utilizaron 200 imágenes (10X) para cada probeta pulida. Los diagramas de cuantificación desarrollados (porcentaje del área de los granos minerales) se presentan en la Figura 7b. Para la veta Vizcaya (Figura 7b: i) los minerales que predominan son esfalerita, calco- a)

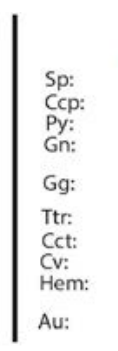

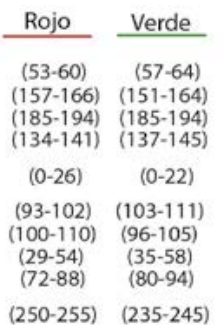
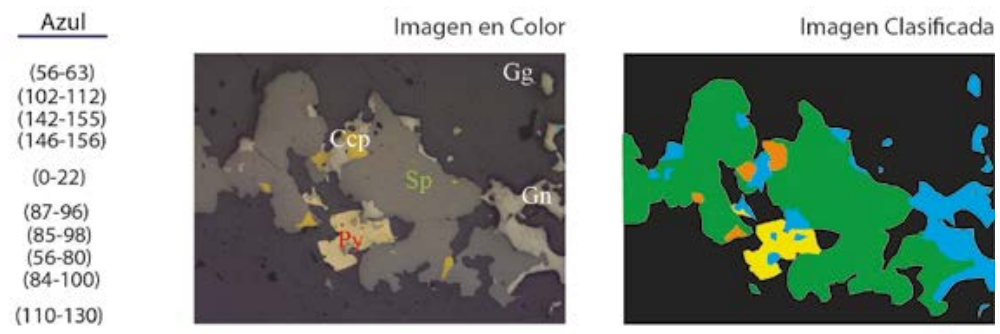

b)
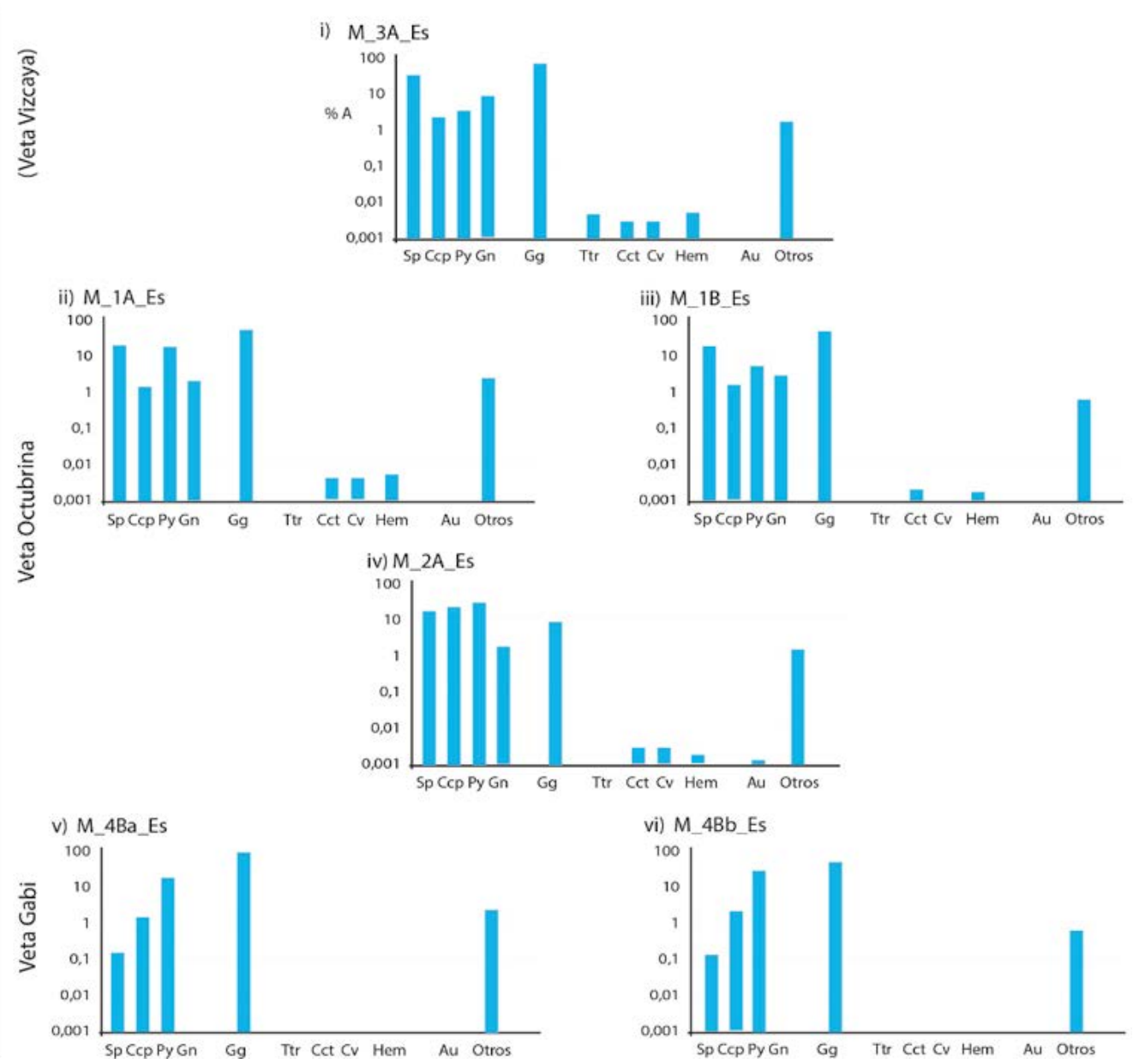

Figura 7. a) Rangos de segmentación calculados y empleados en la identificación automatizada de minerales y ejemplo de clasificación de imagen mediante AOI; b) cuantificación porcentual de área de los granos minerales de probetas pulidas pertenecientes al distrito minero Zaruma-Portovelo. (i) M_3A_Es; (ii) M_1A_Es; (iii) M_1B_Es; (iv) M_2A_Es; (v) M_4B_Es; (vi) M_4Bb_Es.

Figure 7. a) Segmentation values estimated and used in the automatic identification of ore minerals and an example of image classification by OIA; b) percentage quantification of area of the mineral grains of polished sections belonging to the Zaruma-Portovelo mining district. (i) $M \_3 A \_E s$; (ii) $M \_1 A \_E s$; (iii) $M \_1 B \_E s$; (iv) $M \_2 A \_E s$; (v) M_4B_Es; (vi) M_4Bb_Es. 
pirita, pirita y galena. En el caso de los diagramas de la veta Octubrina (Figura 7b: ii, iii y iv), además de la calcopirita, pirita y galena se evidencia la presencia oro en estado libre. Finalmente, en los diagramas (Figura $7 \mathrm{~b}:$ v y vi) de la veta Gabi, resulta destacable la presencia de pirita.

\section{Resultados: Microanálisis mediante microsonda elec-} trónica

La microsonda electrónica permitió conocer la composición química puntual de las diferentes zonas de las fases minerales seleccionadas (132 análisis). Di-

\begin{tabular}{|c|c|c|c|c|c|c|c|c|}
\hline $\begin{array}{l}\text { Punto } \\
\text { Figura }\end{array}$ & $\begin{array}{c}\text { Punto } \\
\text { Anexo } 1\end{array}$ & Muestra & Mineral & $\begin{array}{l}\text { Oro } \\
(\%)\end{array}$ & $\begin{array}{c}\text { Plata } \\
(\%)\end{array}$ & $\begin{array}{c}\text { Cobre } \\
(\%)\end{array}$ & $\begin{array}{c}\text { Arsénico } \\
\text { (\%) }\end{array}$ & $\begin{array}{c}\text { Hierro } \\
(\%)\end{array}$ \\
\hline & & Vizcaya & & & & & & \\
\hline 1 & $35 / 1$ & M_3A_Fs & Pirita & - & 0.0544 & - & - & 45.0674 \\
\hline 2 & $31 / 1$ & M_3A_Es & $\begin{array}{l}\text { Calcopirita- } \\
\text { Esfalerita }\end{array}$ & - & 0.0580 & 31.8751 & 0.0492 & 29.7924 \\
\hline 3 & $39 / 1$ & M_3A_Es & Esfalerita & - & 0.0208 & 0.0357 & - & 0.6610 \\
\hline 4 & $30 / 1$ & M_3A_Es & Galena & 0.1249 & 0.0206 & - & - & - \\
\hline 5 & $28 / 1$ & M_3A_Es & Galena- Pirita & - & - & - & - & 40.4550 \\
\hline \multirow[t]{2}{*}{6} & $41 / 1$ & M 3A Es & Pirita & 0.0399 & - & - & 0.0440 & 46.2753 \\
\hline & & Octubrina-1 & & & & & & \\
\hline 7 & $69 / 1$ & M_1A_Es & Galena & 0.0317 & 0.0450 & - & 0.0498 & 0.1351 \\
\hline 8 & $56 / 1$ & M_1A_Es & Esfalerita & - & - & 1.0288 & 0.0621 & 1.8050 \\
\hline 9 & $73 / 1$ & M_1A_Es & Pirita & 0.0618 & 0.0512 & - & 0.0840 & 46.1224 \\
\hline 10 & $80 / 1$ & M_1A_Es & Calcopirita & 0.0809 & 0.0266 & 31.3766 & 0.0219 & 29.6756 \\
\hline 11 & $77 / 1$ & M_IA_Es & Esfalerita & - & 0.0459 & 0.1192 & - & 0.8785 \\
\hline 12 & $78 / 1$ & M_1A_Es & Pirita & 0.0970 & - & - & - & 46.0152 \\
\hline \multirow[t]{2}{*}{13} & $79 / 1$ & M_1A_Es & Calcopirita & & 0.0360 & 31.9739 & & 29.8129 \\
\hline & & Octubrina-2 & & & & & & \\
\hline 14 & $90 / 1$ & M_1B_Fs & C.alcopirita & 0.2990 & - & 31.7962 & - & 29.5577 \\
\hline 15 & $93 / 1$ & M_1B_Es & Pirita & - & - & 0.0238 & 0.0839 & 46.1395 \\
\hline 16 & $92 / 1$ & M_1B_Es & Pirita & 0.1372 & 0.0240 & - & 0.0357 & 46.1011 \\
\hline 17 & $91 / 1$ & M_1B_Es & Pirita & - & - & 0.0307 & 0.0649 & 45.5980 \\
\hline 18 & $98 / 1$ & M_1B_Es & Calcopirita & 0.0389 & - & 31.9556 & 0.0616 & 30.1352 \\
\hline 19 & $97 / 1$ & M_1R_Fs & C.alcopirita & 0.1589 & 0.0464 & 33.2671 & 0.0603 & 31.2595 \\
\hline 20 & $99 / 1$ & $\begin{array}{l}\text { M_1B_Es } \\
\text { Gabi }\end{array}$ & Pirita & - & - & 0.0462 & 0.0203 & 46.0650 \\
\hline 21 & $129 / 1$ & M_4B_Es & Pirita & - & 0.0568 & $\cdot$ & 0.1942 & 46.1392 \\
\hline 22 & $128 / 1$ & M_4B_Es & Pirita & - & - & - & 0.0435 & 46.2748 \\
\hline 23 & $130 / 1$ & M_4B_Es & Pirita & - & - & - & 0.5620 & 45.0175 \\
\hline 24 & $131 / 1$ & M_4B_Es & Pirita & 0.0226 & 0.1040 & - & 0.0638 & 46.6319 \\
\hline 25 & $132 / 1$ & M_4B_Es & Pirita & - & - & - & - & 47.1505 \\
\hline 26 & $127 / 1$ & M_4B_Es & Pirita & 0.1522 & 0.0534 & 0.0159 & 0.0811 & 46.3001 \\
\hline
\end{tabular}

Tabla 3. Interpretación de datos obtenidos de la microsonda electrónica de los análisis correspondientes a las imágenes de la Figura 6. LOD $\mathrm{Au}=289 \mathrm{ppm}$. LOD Ag=180 ppm.

Table 3. Interpretation of data obtained from the electronic microprobe, data from the image Figure 6. LOD Au=289 ppm. LOD Ag=180 ppm. 
cha composición química se expresa en porcentaje en peso de los elementos químicos. La identificación mineral se llevó a cabo mediante su conversión a las fórmulas químicas y la totalidad de los datos adquiridos, separados por minerales presentes en cada veta (Anexo 1). En general, las mineralizaciones procedentes del filón Vizcaya presentan principalmente esfalerita, pirita, galena y calcopirita. Respecto a las esfaleritas estudiadas, éstas presentan variaciones composicionales de su solución sólida respecto a: Zn, $\mathrm{Fe}, \mathrm{Mn}, \mathrm{Cu}$ y $\mathrm{Cd}$. Se destaca principalmente la existencia de tres tipos de esfalerita en cuanto a sus contenidos medios de $\mathrm{Fe}(1.40 \% ; 2.48 \% ; 10.80 \%)$. Por otro lado, es destacable la ausencia de $\mathrm{Au}$ en todas ellas y la presencia de $\mathrm{Ag}$ (media de $0.029 \%$ ) en el $38 \%$ de las fases inspeccionadas. La pirita en este filón presenta contenidos muy bajos en $\mathrm{Cu}(<0.05 \%)$ y en As ( $<0.06 \%$, media de $0.04 \%)$. Muestran la presencia de Au (media de $0.06 \%$ ) y $\mathrm{Ag}(0.054 \%$ ) en el $50 \%$ y $41 \%$ respectivamente, de las piritas analizadas. La galena presenta Au (media de $0.106 \%$ ) en un $42 \%$ de las partículas analizadas y $\mathrm{Ag}(0.061 \%)$ en un $67 \%$ de las galenas evaluadas. La calcopirita no presenta Au en las partículas analizadas.

En el caso filón Octubrina, la mineralización predominante es similar a la encontrada en el filón Vizcaya: esfalerita, pirita, galena y calcopirita. La esfalerita presenta contenidos de $\mathrm{Fe}$ en un rango de 0.6 a $1.8 \%$ con un contenido medio de $1.00 \%$, ausencia de Au y presencia de $\mathrm{Ag}$ en el $20 \%$ de las partículas evaluadas con un contenido medio del $0.040 \%$. En el caso de las piritas, éstas presentan valores destacables en $\mathrm{Cu}<<$ $0.2 \%)$ y As $(<1.87 \%)$, con una media del $0.14 \%$ más altos que las otras vetas). Las piritas presentan Au en el $45 \%$ de ellas con un contenido medio de $0.075 \%$ y $\mathrm{Ag}$ en el $50 \%$ de las piritas estudiadas (media de $0.04 \%$ ). En el caso de la galena, ésta presenta Au (contenido medio de $0.052 \%$ ) en el $83 \%$ de las partículas y $\mathrm{Ag}$ (media de $0.103 \%$ ) en el $67 \%$ de las partículas. La calcopirita presenta Au en el $41 \%$ las partículas analizadas (media $0.082 \%$ ) y $\mathrm{Ag}$ en el $53 \%$ las partículas analizadas (media de $0.036 \%$ ).

En el caso del filón Gabi, la mineralización identificada corresponde a pirita. Ésta presenta contenidos muy bajos en $\mathrm{Cu}(<0.05 \%)$ y bajos en As $(<0.56 \%$, media de $0.06 \%$ ), presencia de $\mathrm{Au}$ en el $42 \%$ de las partículas analizadas (media de $0.066 \%$ ) y de $\mathrm{Ag}$ en el $60 \%$ de partículas (media de $0.04 \%$ ).

En la Tabla 3 se presenta, de forma simplificada, la interpretación de algunos análisis realizados con microsonda electrónica (ejemplo: fase mineral, valores de oro y plata) sobre partículas minerales de probetas del filón Vizcaya, Octubrina y Gabi (Figura 6).

\section{Interpretación y discusión de los resultados}

El estudio de las muestras de las tres vetas del depósito mineral Zaruma-Portovelo mediante las técnicas de MOp (transmisión y reflexión), MEB, AOI, DRX y EMPA permitió caracterizar de forma cualitativa y cuantitativa la mineralización presente en éstas. La representación de las mineralizaciones definidas para las tres vetas estudiadas, como una interpretación paragenética de éstas, se representa en la Figura 8. Esta interpretación se basó en correlacionar las mineralizaciones y sus particularidades (petrográficas y geoquímicas) considerando estudios previos (ejemplo: Bonilla, 2010; Paladines and Rosero, 1996).

En general, se identificó que algunas de las fases minerales como pirita, galena y calcopirita contenían oro y plata en su estructura cristalina. Esta circunstancia aporta nueva información respecto a lo descrito previamente por Paladines and Rosero (1996), Bonilla (1996), Vikentyev et al. (2005) y Banda et al. (2005) y permite realizar una diferenciación entre las fases con y sin oro en la evolución paragenética de las muestras (Figura 8).

En la veta Vizcaya, la mineralización encontrada en las muestras estudiadas aporta información sobre dos minerales no definidos previamente por Bonilla (2010): la covellina y calcosina. Aunque, sí fueron encontrados en los estudios realizados por Paladines and Rosero (1996) quienes, en su interpretación paragenética, los asignan en un último estadio de mineralización propio de minerales de enriquecimiento secundario. En el presente estudio, se les asigna el estadio 5 . En el caso de la pirita $(1,2$ y 3$)$ y cuarzo medio $(1,2)$ las técnicas utilizadas permitieron la identificación de sus variaciones dentro de la interpretación paragenética (Figura 8).

El estudio petrográfico permitió, en el caso de la pirita, establecer tres fases (pirita 1 como cristales subhedrales diseminados en pirita, pirita 2 de tipo masiva sin oro y pirita 3 con contenidos en oro) aunque en el estudio de microsonda solo 2 fases ( $\sin$ oro y con oro) se pudieron caracterizar. En el caso de la esfalerita, el estudio mediante microsonda electrónica permitió definir tres fases (basadas en sus contenidos en Fe), a diferencia de las dos establecidas mediante los estudios petrográficos sobre las mismas muestras (esfalerita 1 aparece como resultado de su reemplazamiento por pirita y con forma anhedral mientras que la esfalerita 2 presenta importantes exsoluciones de calcopirita) y también descritos en estudios preliminares (Bonilla, 2010). Respecto a la galena, dos tipos de galena fueron definidos a partir de la presencia de oro en ésta. Una galena 1 sin oro asignada al estadio 3 (Bonilla, 2010) y una galena 2 con oro $(0.05 \%)$ también asignada al estadio 3 de mineralización (Paladines and Rosero, 1996). En el caso de los cuarzos, petrográficamente se distinguieron tres tipos de cuarzo (masivo primario fino, drusiforme grueso y masivo grueso rellenando al drusiforme). Al resto de minerales identificados no se les pudo establecer directamente sus variaciones en el contexto de evolución paragenética.

En el caso del filón Octubrina, los minerales de covellina y calcosina también aparecen en las muestras estudiadas $y$, al igual que en el filón Vizcaya, el esta- 
dio al que pertenecerían correspondería al estadio 5 (Paladines and Rosero, 1996). En este filón también pudieron ser identificados dos tipos de pirita $(1$ y 2 , según su contenido o no de oro), un tipo de esfalerita (1 y/o 2), dos tipos de galenas ( 1 y 2 , según su contenido en oro-plata o no) y dos de cuarzo medio ( 1 y 2, con contenido en oro- plata o no). En cuanto al cuarzo, el estudio petrográfico permitió proponer tres fases (cuarzo fino y masivo sin oro, cuarzo medio y drusiforme sin oro, un cuarzo medio y masivo con oro). Sin embargo, a diferencia de lo encontrado en la veta Vizcaya, en la veta Octubrina se encontró oro en estado libre (Vikentyev et al. 2005; Berrezueta et al. 2016) dentro del cuarzo de grano medio (oro 3 según Bonilla, 2010) y presencia de oro en la estructura cristalina de calcopirita (calcopirita 2).

En el filón Gabi se encuentran principalmente dos minerales: pirita y cuarzo. El estudio de las muestras de este filón permitió la identificación de dos tipos de pirita ( 1 y 2 , según su contenido en oro-plata o no) y tres tipos de cuarzo al igual que en las vetas Vizcaya y Octubrina.
En general, la información obtenida de las muestras ha permitido establecer una relación con dos de las tres principales zonas de mineralización definidas para el depósito por Banda et al. (2005) y Vikentyev et al. (2005): a) zona con predominio de sulfuros y presencia de oro y b) zona con predominio de sulfosales y presencia de oro. La estimación de la abundancia de las principales fases minerales ( $\mathrm{Ccp}$, Py y $\mathrm{Gn}$ ) con contenido en $\mathrm{Au}$, mediante $\mathrm{AOl}$ y empleando los datos de EMPA (Anexo 1), se presentan en la Figura 9. En términos cuantitativos, los resultados obtenidos para la veta Vizcaya reflejan que un $6.10 \%$ del $13.08 \%$ de Ccp, Py y Gn tiene contenidos de Au. En el caso de la veta Octubrina, un $8 \%$ del $15.49 \%$ de Ccp, Py y Gn tiene contenidos de Au. Finalmente, la veta Gabi presenta un $5.1 \%$ del $14.37 \%$ de Ccp, Py y $\mathrm{Gn}$ con contenidos de Au. La información obtenida, aunque generada en este trabajo con un carácter orientativo y representativo a escala de la probeta pulida, aporta una información relevante para la planificación de actividades de concentración mineral de la mina estudiada. El proceso de cuantificación

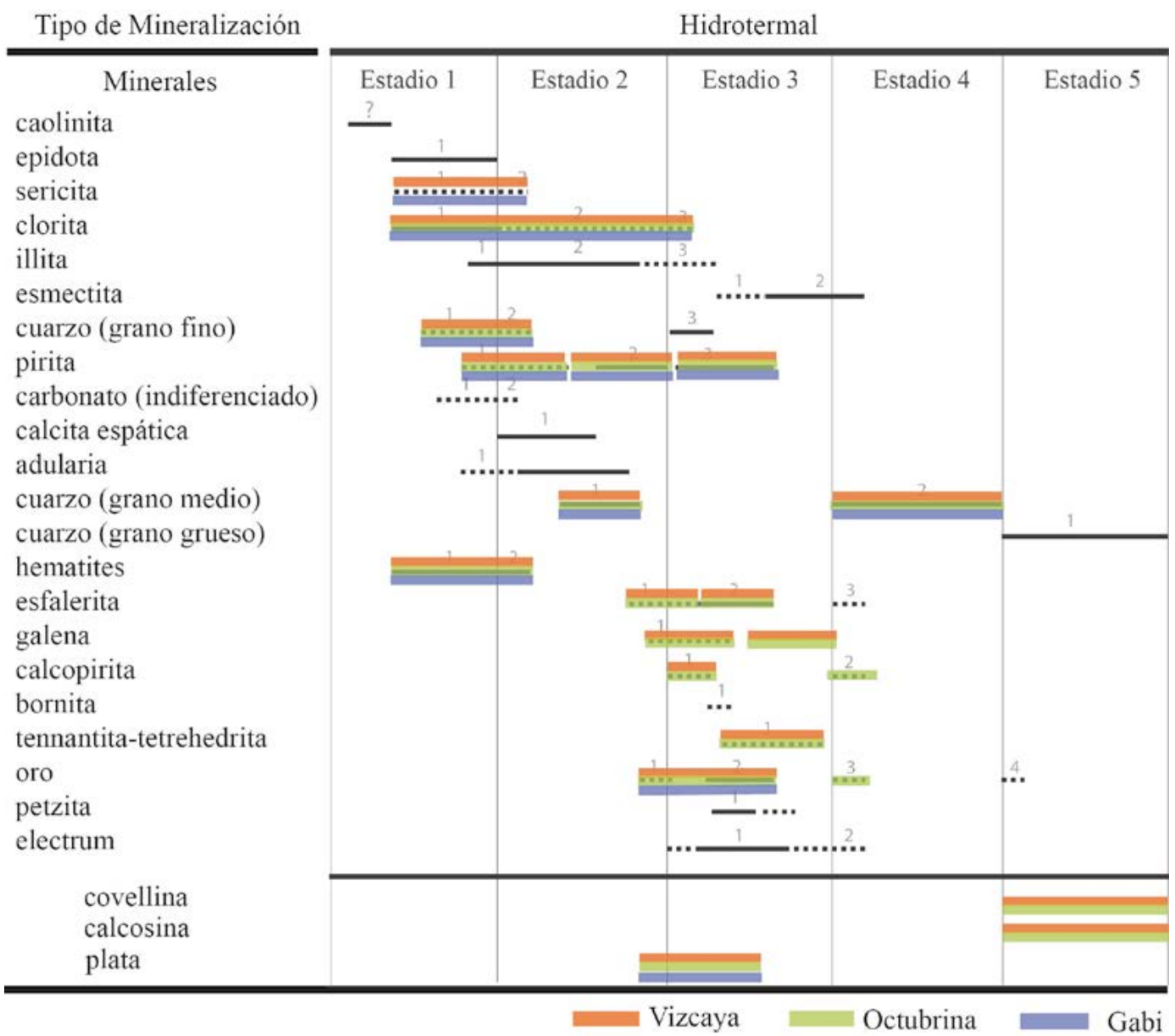

Figura 8. Paragénesis mineral definida para las vetas Vizcaya, Octubrina y Gabi. Representación de la paragénesis superpuesta al modelo definido por Bonilla (2010).

Figure 8. Mineral paragenesis defined for the Vizcaya, Octubrina and Gabi veins. Representation of the mineral paragenesis on a model defined by Bonilla (2010). 
propuesto (combinar AOI con EMPA en la medición de asociaciones minerales) podría permitir obtener detalles más específicos y automatizados en la optimización geometalúrgica como: grado de liberación mineral, tamaño y distribución del grano mineral y datos texturales.

Veta Vizcaya
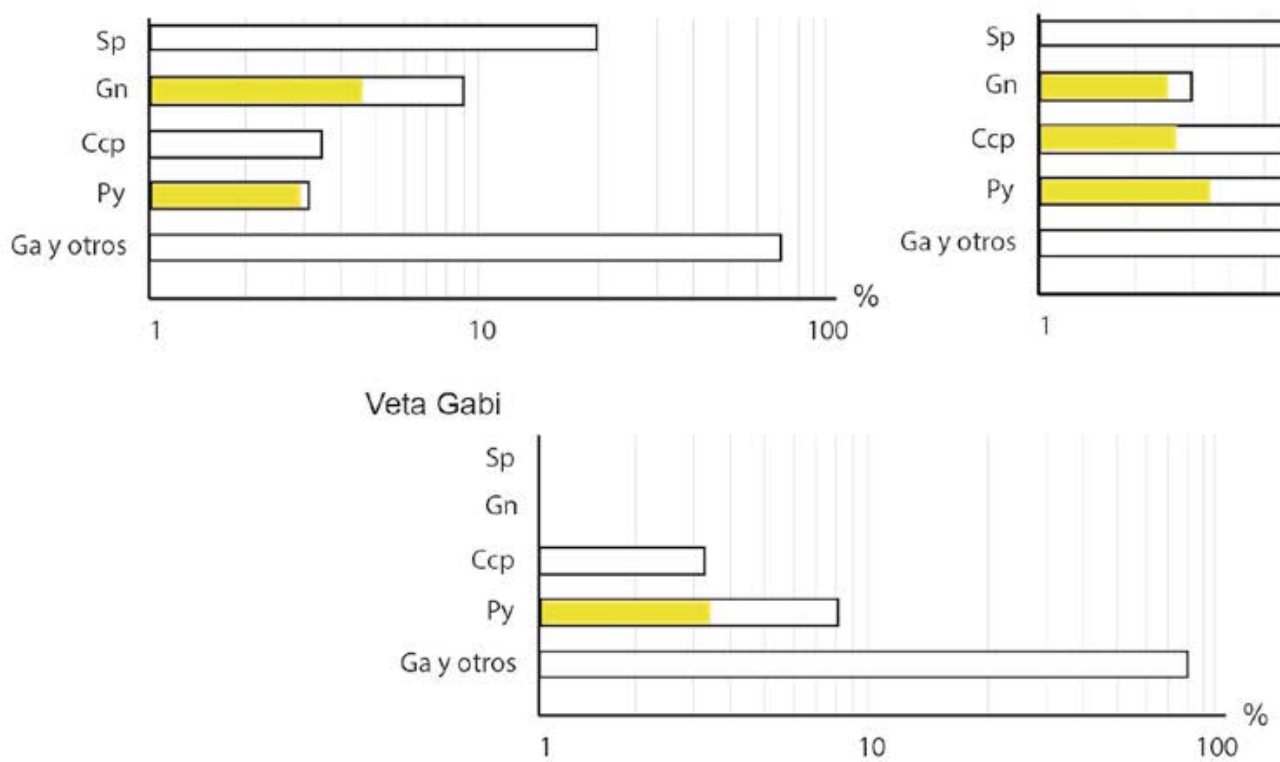

\section{Agradecimientos.}

Este trabajo fue realizado en el marco de la Red Minería XXI (CYTED: 310RT0402). Los autores agradecen a Ricardo Castroviejo Bolibar (Universidad Politécnica de Madrid) y a Jesús García Nieto (Consultor Autó-

\section{Veta Octubrina}

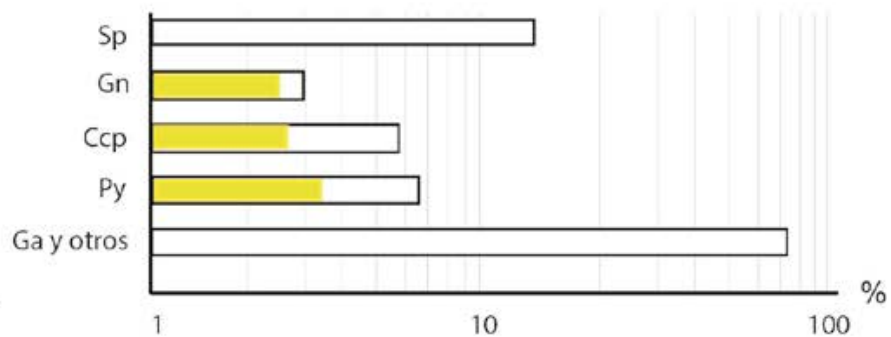

según su contenido en oro (Au).

Figure 9. Diagrams of abundance (\%) of the main sulphides found: sphalerite (Sp), chalcopyrite (Ccp), pyrite (Py) and galena (Gn), according to their content in Gold (Au).

\section{Conclusiones}

Desde el punto de vista metodológico, las técnicas utilizadas (MOp, AOI, DRX y EMPA) en la caracterización de las muestras procedentes de las tres vetas evaluados han permitido de forma eficiente la identificación y cuantificación de las principales fases minerales. Además, las técnicas aplicadas aportaron información mineralógica y petrográfica que permitió i) relacionar las mineralizaciones descritas con estudios paragenéticos previos y ii) aportar información complementaria a la hora de definir un modelo de evolución de las mineralizaciones estudiadas y cuantificar los tipos de asociación mineral presente.

Desde el punto de vista de los resultados obtenidos, fue posible establecer que, de acuerdo a las mineralizaciones y asociaciones minerales encontradas, éstas se corresponden con un depósito epitermal de sulfuración intermedia, tal como se describe en la literatura científica y que, en concreto, las muestras estudiadas (frentes de trabajo minero en las vetas Vizcaya, Octubrina y Gabi) se corresponden a los estadios de mineralización con valor económico. Es decir, en los estadios (2-3-4) donde se produjo el depósito de sulfuros polimetálicos con contenidos de oro y plata-oro. nomo) por sus sugerencias y recomendaciones en la redacción de este manuscrito. También se agradece a Oscar Loor (Bira S.A) su ayuda y autorización para el uso y recolección de muestras de la Mina de Oro. Los autores quieren agradecer a dos revisores anónimos y al comité editorial por las sugerencias proporcionadas. In Memorian de Wilson Bonilla. Los autores quieren agradecer a dos revisores anónimos y al comité editorial por las sugerencias proporcionadas.

\section{Referencias}

Albinson, T., Norman, D. I., Cole, D. and Chomiak, B. 2001. Controls on formation of low-sulfidation epithermal deposits in Mexico. In: Albinson, T. and Nelson, C.E. (eds.), Constraints from fluid inclusion and stable isotope data, in New mines and discoveries in Mexico and Central America, SEG, USA, 32.

Banda, R., Vikentyev, I.V. and Nosik, L.P. 2005. Sulfur isotopic composition of the Vizcaya and Nikol veins, Portovelo Zaruma deposit, Ecuador. Doklady Earth Sciences, 405 A (9), 1388-1392.

Berrezueta, E., Ordóñez-Casado, B., Bonilla, W., Banda, R., Castroviejo, R., Carrión, P. and Puglla, S. 2016. Ore Petrography Using Optical Image Anal- 
ysis: Application to Zaruma-Portovelo Deposit (Ecuador). Geosciences, 6(4), 30.

Billingsley, P. 1926. Geology of the Zaruma gold district of Ecuador. American Institute of Mining and Metallurgical Engineering, 74(1601), 255-275.

Bonilla, W. 1996. Vizcaya de Ecuador: Historia de una veta aurífera. Revista Latino Minería, 21, 67-75.

Bonilla, W. 2002. Geocronología y Eventos de Brechificación de la Veta Polimetálica Vizcaya, suroeste de Ecuador. VI Congreso de Mineralogía y Metalogenia. Universidad de Buenos Aires, Argentina, 35-39.

Bonilla, W. 2010. Metalogenia del distrito minero Zaruma-Portovelo, República del Ecuador, Tesis Doctoral, Universidad de Buenos Aires, Argentina, 218 págs.

Castroviejo, R. and Berrezueta, E. 2009. Reconocimiento automatizado de menas metálicas mediante análisis digital de imagen: un apoyo al proceso mineralúrgico. II: criterios metalogenéticos discriminantes. Revista de Metalurgia, 45 (6), 439-456.

Castroviejo, R., Chacón, E., Múzquix, C. and Tarquini, S. 1999. A preliminary image analysis characterization of massive sulphide ore from SW Iberian Pyrite Belt (Spain). Geovision 99, International Symposium on Imaging Applications in Geology, Liège, Belgium, 37-40.

Chiaradia, M., Fontbote, L. and Beate, B. 2004. Cenozoic continental arc magmatism and associated mineralization in Ecuador. Mineralium Deposita, 39 (2), 204-222.

Chopped, A., Marion, P., Royer, J., Taza, R., Bouzahzah, H. and Benzaazoua, M. 2019. Automated sulfides quantification by multispectral optical microscopy. Minerals Engineering, 131, 38-50.

Craig, J.R. and Vaughan, D.J. 1994. Ore microscopy and ore petrography. New York: 2da Edición, Wiley, 424 págs.

Criddle, A.J. 1990. The reflected-light polarizing microscope and microscope-spectrophotometer. Advanced Microscopic Studies of Ore minerals. Short Course Handbook, 17, 1-36.

Echavarría, L., Schalamuck, I. and Etcheverry, R.O. 2005. Geologic and tectonic setting of Deseado Massif epithermal deposits, Argentina, based on El Dorado-Monserrat. Journal of South American Earth Sciences, 19 (4), 415-432.

Einaudi, M., Hedenquist, J.W. and Inan, E.E. 2005. Sulfidation State of Fluids in Active and Extinct Hydrothermal Systems: Transitions from Porphyry to Epithermal Environments. In: F. S. Simmons, I. Graham (eds.), Volcanic, Geothermal, and Ore-Forming Fluids: Rulers and Witnesses of Processes within the Earth, SEG, USA, 50.

Fontaine, F., Wilcock, W., Foustoukos, D. and Butterfield, D. 2009. A Si-Cl geothermobarometer for the reaction zone of high-temperature, basaltic-hosted mid-ocean ridge hydrothermal systems. Geochemistry, Geophysics, Geosystems, 10 (5), 1-9.

Fournier, R.O. 1999. Hydrothermal Processes Related to Movement of Fluid From Plastic into Brittle Rock in the Magmatic-Epithermal Environment. Economic Geology, 94 (8), 1193-1211.

Gao, S., Xu, H., Zhang, D., Shao, H. and Quan, S. 2014. Ore petrography and chemistry of the tellurides from the Dongping gold deposit, Hebei Province, China. Ore Geology Reviews, 64, 23-34.

Gemmell, J.B., Simmons, S.F. and Zantop, H. 1988. The Santo Nino silver-lead-zinc vein, Fresnillo District, Zacatecas, Mexico; Part I, Structure, vein stratigraphy, and mineralogy. Economic Geology, 83 (8), 1597-1618

Heald, P., Hayba, D.O. and Foley, N.K. 1987. Comparative anatomy of volcanic-hosted epithermal deposits: acid-sulfate and adularia-sericite types. Economic Geology, 82, 1-26.

Hedenquist, J. 2001. Types of sulfide-rich epithermal deposits, and their affiliation to porphyry systems: Lepanto-Victoria-Far Southeast deposits, Philippines, as examples. ProExplo Congreso, Lima, Perú, 24-28.

Hedenquist, J., Arribas, A. and Urien-González, F. 2000. Exploration for epithermal gold deposits. In: Hagemann, S.G., Brown, P.E. (eds.), Gold in 2000: Society of Economic Geologist, Review in Economic Geology, Colorado, USA, 245-277

Honeyands, T., Manuel, J., Matthews, L., O'Dea, D., Pinson, D., Leedham, J. and Donskoi, E. 2019. Comparison of the Mineralogy of Iron Ore Sinters Using a Range of Techniques. Minerals, 9(6), 333.

Hrstka, T., Gottlieb, P., Skala, R., Breiter, K. and Motl, D. 2018. Automated mineralogy and petrology-applications of TESCAN Integrated Mineral Analyzer (TIMA). Journal of Geosciences, 63(1), 47-63.

John, D.A., Garside, L.J., and Wallace, A.R. 1999. Magmatic and tectonic setting of late Cenozoic epithermal gold-silver deposits in northern Nevada, with an emphasis on the Pah Rah and Virginia Ranges and the northern Nevada rift. In: Kizis, J.A.Jr., (eds). Low-sulfidation gold deposits in northern Nevada. Spring Field Trip Guidebook, Special Publication No. 29: Reno, Geological Society of Nevada, USA, p. 64-158.

Kay, S.M., Mpodozis, C. and Coira B. 1999. Neogene magmatism, tectonism and mineral deposits of the Central Andes (22 to 33 S latitude). In: Skinner B.J. (ed.), Geology and ore deposits of the Central Andes. SEG, USA, 27-59.

Kehl, G. 1954. Fundamentos de la Práctica Metalográfica. 3ra. Edición, Editorial Aguilar, España.

Köse, C., Alp, I. and Ikibas, C. 2012. Statistical methods for segmentation and quantification of minerals in ore microscopy. Minerals Engineering, 30, 19-32.

Leroy, S. and Pirard, E. 2019. Mineral recognition of single particles in ore slurry samples by means of multispectral image processing. Minerals Engineering, 132, 228-237.

Litherland, M. and Aspden, J. 1992. Terrane-boundary reactivation: $A$ control on the evolution of the 
Northern Andes. Journal of South American Earth Sciences, 5(1), 71-76.

Meyer, C. and Hemley, J.J. 1967. Wall rock alteration. In: Barnes, H.L. (ed.), Geochemistry of hydrothermal ore deposits. Holt, Rinehart and Winston, New York-London, 166-235.

Paladines, A. and Rosero, G. 1996. Zonificación mineralógica del Ecuador. Láser, Quito, 146 pp.

Pearson, M.F., Clark, K.F. and Porter, E.W. 1988. Mineralogy, fluid characteristics, and silver distribution at Real de Angeles, Zacatecas, Mexico. Economic Geology, 83, 1737-1759.

Ramdohr, P. 1969. The ore minerals and their inter growths. Pergamon, New York, 1192 pp.

Reeves, E., Seewald, J., Saccocia, P., Bach, W., Craddock, P.R., Shankse, W. and Rosner, M. 2011. Geochemistry of hydrothermal fluids from the PACMANUS, Northeast Pual and Vienna Woods hydrothermal fields, Manus Basin, Papua New Guinea. Geochimica et Cosmochimica Acta, 75 (4), 1088-1123.

Rusk, B.G., Reed, M.H. and Dilles, J.H. 2008. Fluid Inclusion Evidence for Magmatic-Hydrothermal Fluid Evolution in the Porphyry Copper-Molybdenum Deposit at Butte, Montana. Economic Geology, 103 (2), 307-334.

Simmons, S., White, N.C. and John, D. A. 2005. Geological Characteristics of Epithermal Precious and Base Metal Deposits. In: Hedenquist, J.W.; Thompson, J.F.H.; Goldfarb, R.J.; Richards, J. P. (eds.). Economic Geology One Hundredth Anniversary Volume: 1905-2005, Society of Economic Geologists, Littleton, CO, USA, p. 485-522.

Song, G., Cook, N.J., Wang, L., Quin, K., Ciobanu, C.L. and Li, G. 2019. Gold behavior in intermediate sul- fidation epithermal systems: A case study from the Zhengguang gold deposit, Heilongjiang Province, NE-China. Ore Geology Reviews, 106, 446-462.

Spencer, R.M., Montenegro, J.L. Gaibor, A., Pérez, E.P., Mantilla, G., Viera, F. and Spencer, C.E. 2002. The Portovelo-Zaruma mining camp, SW Ecuador: porphyry and epithermal environments. SEG Newsletter, 49(1), 8-14.

Surour, A.A., Bakhsh, R.A. and El-Nisr, S.A. 2014. Ore microscopic characterization of mineralized rocks at the Bi'r Tawilah gold prospect, Saudi Arabia. Journal of Microscopy and Ultrastructure, 2(1), 4155.

Van Thournout, F., Salemink, J., Valenzuela, G., Merlyn, M., Boven, A. and Muchez, P. 1996. Portovelo: a volcanic-hosted epithermal vein-system in Ecuador, South American. Mineralium Deposita, 31(4), 269-276.

Vikentyev, I., Banda, R., Tsepin, A., Prokofiev, V. and Vikentyev, O. 2005. Mineralogy and formation conditions of Portovelo-Zaruma gold-sulphide vein deposit, Ecuador. Geochemistry, Mineralogy and Petrology, 43, 148-154.

Von Damm, K.L. 2004. Evolution of the Hydrothermal System at East Pacific Rise $9^{\circ} 50^{\prime} \mathrm{N}$ : Geochemical Evidence for Changes in the Upper Oceanic Crust. In: C.R German, J. Lin, L.M. Parson (eds.), Mid Ocean Ridges: Hydrothermal Interactions Between the Lithosphere and Oceans, AGU, Washington, D. C., 285-304.

Wang, L., Qin, K., Song, G. and Li, G. 2019. A review of intermediate sulfidation epithermal deposits and subclassifications. Ore Geology Reviews, 107, 434-456.

Whitney, D. and Evans, B. 2010. Abbreviations for Names of Rock-Forming Minerals. American Mine-
Recibido: julio 2020

Revisado: diciembre 2020

Aceptado: enero 2021

Publicado: diciembre 2021 
ralogist, 95(1), 185-187. 